\title{
Less is more: strategies to remove marker genes from transgenic plants
}

\author{
Yuan-Yeu Yau ${ }^{1}$ and C Neal Stewart Jr ${ }^{2^{*}}$
}

\begin{abstract}
Selectable marker genes (SMGs) and selection agents are useful tools in the production of transgenic plants by selecting transformed cells from a matrix consisting of mostly untransformed cells. Most SMGs express protein products that confer antibiotic- or herbicide resistance traits, and typically reside in the end product of geneticallymodified (GM) plants. The presence of these genes in GM plants, and subsequently in food, feed and the environment, are of concern and subject to special government regulation in many countries. The presence of SMGs in GM plants might also, in some cases, result in a metabolic burden for the host plants. Their use also prevents the re-use of the same SMG when a second transformation scheme is needed to be performed on the transgenic host. In recent years, several strategies have been developed to remove SMGs from GM products while retaining the transgenes of interest. This review describes the existing strategies for SMG removal, including the implementation of site specific recombination systems, TALENs and ZFNs. This review discusses the advantages and disadvantages of existing SMG-removal strategies and explores possible future research directions for SMG removal including emerging technologies for increased precision for genome modification.
\end{abstract}

Keywords: Biosafety, Clean-gene technology, Co-transformation, Homologous recombination, Intra-chromosomal recombination, Marker-free, Meganuclease, Negative selection, Site-specific recombination, TAL effector nucleases, Transposons, Zinc finger nuclease

\section{Review}

Since the first recombinant DNA was successfully created through the removal of a specific gene from a bacterium and inserting it into another bacterium by the use of the restriction enzyme in 1973 [1], recombinant DNA technology has emerged as a powerful tool for editing genes and genetic elements in vectors to produce novel recombinant DNA products. In 1978, scientists from Genentech successfully used engineered bacteria to produce human insulin, which became the first commercial biopharmaceutical product on the market. Following the continuous improvement of DNA technology and the application of Agrobacterium for transgene delivery, the first transgenic plants were successfully generated by four independent groups in the early 1980s [2-5]. In 1994, the first commercialized genetically modified (GM) plant product, Calgene's 'FLAVR SAVR' tomato,

\footnotetext{
* Correspondence: nealstewart@utk.edu

2Department of Plant Sciences, University of Tennessee, Knoxville, TN 37996 , USA

Full list of author information is available at the end of the article
}

was sold on the market. Today genetic transformation in plants has become routine; more than 100 agricultural crops have been genetically modified in research stations around the world (http://sbc.ucdavis.edu/B4S/ B4S.html). According to the International Service for the Acquisition of Agri-Biotech Applications (ISAAA), the global area used for cultivating transgenic crops has grown to 160 million hectares in 2011, an 94-fold increase from 1996 to 2011. GM technology has not only become an important plant breeding tool, but has great potential humanitarian impact on developing countries for food security [6].

Although transgenic crop adoption has been increasing, the fact that a selectable marker gene (SMG, usually an antibiotic- or herbicide-resistant gene [7]) remains in the genomes of GM plants has raised concerns from both regulatory agencies and the public in certain countries. These concerns include the potential impact on transgenic crops for both food safety and the environment. Among the most controversial concerns is that a SMG coding for an antibiotic resistance originally from
C Biomed Central

(c) 2013 Yau and Stewart; licensee BioMed Central Ltd. This is an Open Access article distributed under the terms of the Creative Commons Attribution License (http://creativecommons.org/licenses/by/2.0), which permits unrestricted use, distribution, and reproduction in any medium, provided the original work is properly cited. 
a bacterium might be horizontally transferred from GM plants back to bacteria causing new antibiotic resistance problems, for example, in the human- or animal gut environment. The main question is can pathogenic microbes receive GM plant SMGs through horizontal gene transfer and cause new problems, i.e., increasing the possibility of compromising the clinical effectiveness of antibiotic drugs? The increasing number of cases of bacteria that have evolved antibiotic resistance, such as methicillinresistant Staphylococcus aureus (MRSA) (www.cdc.gov), has undoubtedly led to consumer concern.

The second concern is gene flow from GM crop to another crop or wild relative, and especially the introgression of SMGs where they might either increase fitness and persistence [8] or render a population at risk; i.e., the worst case scenario, extinction [9]. Although gene flow is a natural process [10], SMGs do not naturally exist in plants and they confer novel traits such as antibiotic- or herbicide-resistance. Therefore, it has been argued that it is desirable to confine transgene(s) in GM crop populations of interest to minimize gene flow to other related species. The gene flow of an herbicideresistance gene (bar) has been studied in Canada in herbicide-resistant canola (Brassica napus) fields. Transgene flow from commercial herbicide-resistant canola to its weedy ancestor Brassica rapa was observed [11]. Both escaped transgenic $B$. napus and hybrids from hybridization of $B$. napus to its related species were identified outside the crop field boundaries. A more recent study showed that a drift level of herbicide (glyphosate) can also function as a selective agent to increase the persistence of transgenes in environment [12].

Because of these concerns, strict regulations are usually applied in the facilities that work on transgenic organisms. In the case of the USA which has the most GM crops grown, NIH guidelines for biosafety containment levels for plants (BL1-P to BL4-P) must be followed for researchers handling recombinant DNA in plants in laboratories (http://oba.od.nih.gov). In addition, before the release of GM plants from laboratories for field trials, permits are required and strict rules are set out for transgene containment (http://usbiotechreg.nbii.gov). Although, so far, research results have not shown evidence that food from transgenic crops has negative impacts on human or animal health [13], and although transgene-flow can be reduced by careful field designs [14], much uncertainty still exists. Some concern and uncertainty might be assuaged by the removal of SMGs once they are no longer needed. Therefore, the production of SMG-free transgenic crops, a so-called 'clean-gene technology', is becoming an extremely attractive alternative and could be a positive factor to contribute to the public acceptance of transgenic crops.

Other benefits from the removal of SMGs from transgenic crops are as follows. (1) The same SMG can be recycled for reuse in subsequent plant transformation projects; e.g., incremental transgene stacking $[15,16]$. There are few candidate SMGs-selection agent pairs for most crops $[17,18]$, thus, it would be expedient to recycle SMGs. (2) The removal of metabolic burden from unwanted SMG expression on the plants, especially those that are highly expressed. For example, the SMG FLARE was reported to accumulate to $18 \%$ of total soluble cellular protein in plants whose plastids were transformed [19]. Therefore, the development of strategies to produce SMG-free transgenic plants is an important objective in plant biotechnology research.

In this review, we discuss several approaches that have been developed to generate SMG-free GM plants, with a focus on what we consider to be the most promising recently developed technologies. We discuss site-specific recombination systems, which have been used to remove SMGs from model plants and crops species [20]; commercial SMG-free maize 'LY038', which has increased free lysine in the germ portion of the grain [21]. We also discuss the use of the most recent zinc finger nuclease (ZFN) and transcription activator-like nuclease (TALEN) technologies to remove SMGs, and the possibility of combined use of ZFNs and site-specific recombination to remove a gene from a desired genomic location.

There are three basic approaches in producing SMGfree transgenic plants. They are: (1) avoidance of SMGs, (2) integration of an SMG and genes of interest (GOI) on unlinked genomic loci during transformation so that the SMG can be segregated away from the GOI, and (3) integration of an SMG and GOI on the same locus, but molecular tools are used for SMG removal. We will assess the current progress for each of these strategies and speculate on the future utility of each.

\section{Avoidance of SMGs in plant transformation}

Because the transformed plant cells carry T-DNA(s) with known sequence, it is possible to distinguish transformed from non-transformed plants using PCR. De Vetten et al. used two different Agrobacterium tumefaciens strains (LBA4404 and AGL0) to transform potato $c v$. Kanico without any selection [22]. The transformation frequency was $0.2 \%$, based on PCR for putative transgenic shoots, using LBA4404 and $4.5 \%$ for AGL0. Stable transformation frequency was reduced approximately by half in this system. Genetic transformation of barley without using any SMG has also been performed [23]. The transformation frequency without selection is $0.8 \%$ when Agrobacterium inoculation of ovules was performed. For comparison, the transformation with selection (hygromycin) frequency was $3.1 \%$. Kim et al. transformed potato with chloroplast-targeted $S O D$ and $A P x$ genes, driven by oxidative-stress-inducible promoters [24]. The transformation efficiency was $2.2 \%$ 
without any selection. Recently, Li et al. reported a tobacco transformation efficiency of $2.2 \%-2.8 \%$ for the most effective binary vector they used in the experiment without selection and over $90 \%$ transformation efficiency with selection [25]. To date, the data demonstrate that although it is achievable to obtain transgenic plants without using selection, the majority of the screened plants would be un-transformed, and thus, not using an SMG at all is very laborious and useful for just a few plant species.

\section{Co-transformation (transfer GOI and SMG separately) and segregation}

Two T-DNAs on two binary vectors

For this strategy, the gene of interest (GOI, such as a trait gene) and an SMG are cloned into two separate transformation vectors, and subsequently the GOI and the SMG are transferred separately into plant tissues using Agrobacterium-mediated transformation [26,27] or particle bombardment [28]. The rationale of this approach is that after transformation, a portion of the
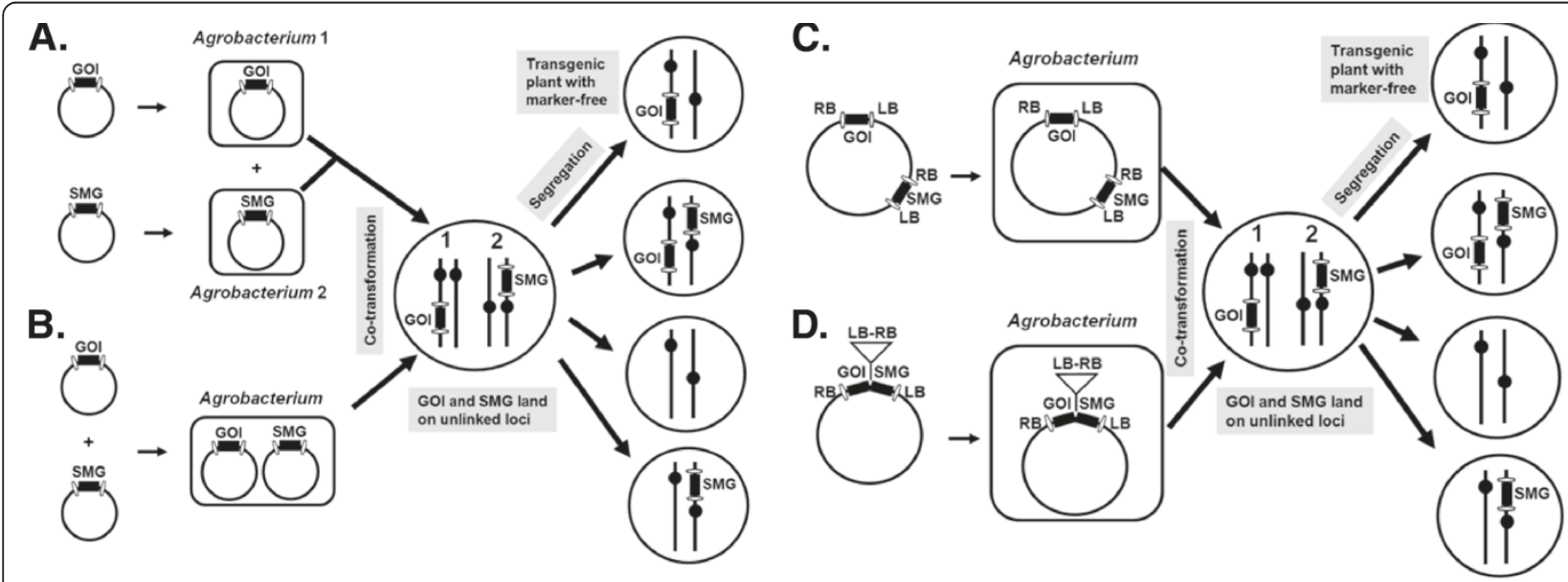

E.

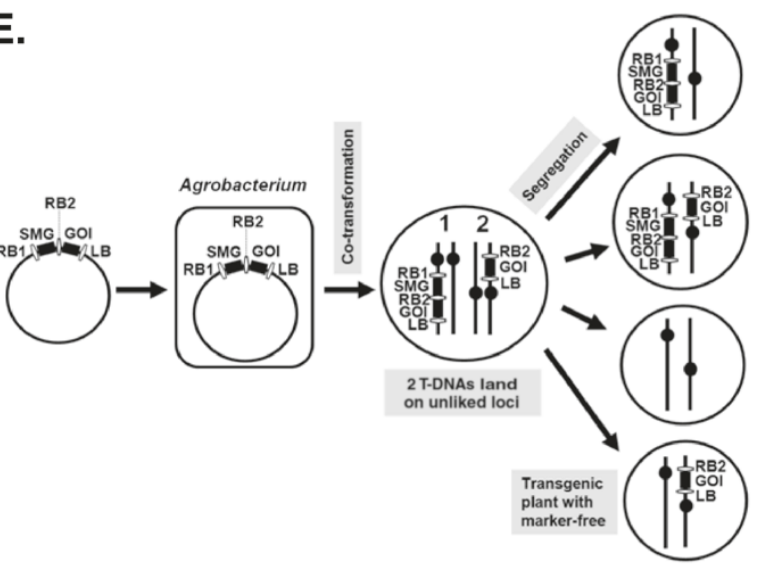

F.

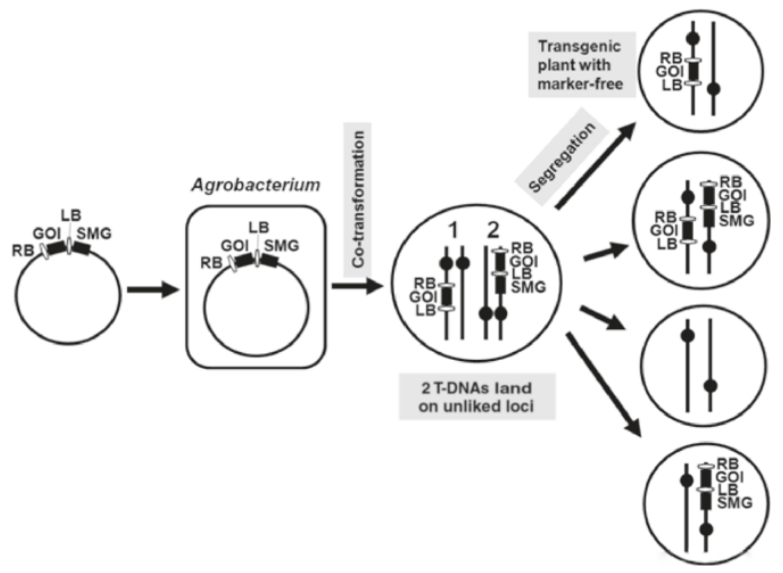

Figure 1 Approaches for co-transformation to produce selectable marker gene (SMG)-free transgenic plants. After the GOI and SMG are integrated on unlinked loci, marker-free transgenic plants can be obtained in the sequential generation after genetic segregation. (A) Mixture method of Agrobacterium co-transformation. Two Agrobacterium strains each contain a transformation vector. One vector has the GOI and the other has the SMG, which are used together to co-transform plants. (B) One-strain method of Agrobacterium co-transformation. One Agrobacterium contains two transformation vectors: one with the GOI and the other one with the SMG. (C) Super binary vector for cotransformation. The super binary vector contains separated T-DNA constructs: one with the GOI and the other with the SMG. (D) Two pairs of right borders and left borders used for co-transformation. A small right border-left border fragment is inserted into the polylinker of a standard binary vector in between a $\mathrm{GO}$ and an SMG, which are already present in another set of left border and right border. (E) Double 'RB' T-DNA approach for co-transformation. The vector is designed in such a way that two right borders (RB1 and RB2) and one left border (LB) are presented as depicted in the figure. Two T-DNA fragments (RB1-SMG-RB2-GOI-LB and RB2-GOI-LB) may be transferred and be integrated on unlinked loci. (F) 'Read-through' method for co-transformation. The SMG is placed outside the left border. T-DNA fragment transfers to plant genome could be RB-GOI-LB or RB-GOI-LB-SMG (a 'read through' product). If RB-GOI-LB or RB-GOI-LB-SMG is integrated on unlinked loci, markerfree transgenic plants can be obtained through genetic segregation. Abbreviations. RB: T-DNA right border, LB: T-DNA left border, GOI: gene of interest, SMG: selectable marker gene. 
resistant transgenic plants surviving antibiotic (or herbicide) selection should have also taken up the GOIcontaining T-DNA cassette. Those transgenic plants with both SMG and GOI are allowed to set seeds for the next generation. By segregating away the SMG which is, hopefully, unlinked to the GOI in the subsequent generation, plants with only the GOI can be obtained.

Agrobacterium-mediated transformation has been used more often than particle bombardment for cotransformation. Two methods to co-transform the separate vectors by Agrobacterium have been reported. (1) The mixture method uses co-transformation of two different Agrobacterium strains each with a transformation vector whereby one carries the SMG and the other the GOI (Figure 1A). (2) The one-strain method transforms an Agrobacterium strain that carries two expression vectors, whereby one carries the SMG and the other the GOI (Figure 1B) (http://www.isaaa.org. Pocket K. No. 36 Marker-Free GM Plants). De Block and Debrouwer evaluated a large number of canola plants that were cotransformed using Agrobacterium and found that when the T-DNAs were delivered by the mixture method, co-transformation occurs often, but in most cases, the T-DNAs were genetically linked [26]. In contrast, Komari et al. [27] reported that the co-transformation frequency of two T-DNAs was greater than $47 \%$ using the one-strain method. Up to $25 \%$ of the co-transformed T-DNAs were unlinked.

\section{Two T-DNAs on one binary vector}

A single Agrobacterium strain that harbors dual T-DNAs for transformation on a single plasmid, known as the two-T-DNA strategy has also been used with the intention of the two T-DNAs integrating independently as they do for co-transformation in biolistics [28]. Two variants are the super binary vector strategy and the twin T-DNAs strategy.

\section{The super binary vector method}

In this strategy, two T-DNA constructs are produced on a single binary vector in such a way that they are separated with an intervening DNA fragment (Figure 1C). The GOI and the SMG are transferred into plant cells independently through Agrobacterium-mediated transformation. Komari et al. [27] developed a 50-55 kb 'super binary' transformation vector with two T-DNA regions that were separated by at least $15 \mathrm{~kb}$. More than $50 \%$ progeny contained only the GOI, without the SMG.

Streamlined binary vectors, such as the 'twin T-DNA' standard binary vector system [29], were created for cotransformation to obtain SMG-free transgenic crops, with the goal of increasing efficiency by decreasing total vector size. Subsequently, Zhou et al. [30] produced an intermediate-sized double T-DNA binary vector from two popular binary vectors (pBin19 and pCAMBIA2300) for co-transformation to produce SMG-free transgenic tobacco. Most recently, a standard binary vector $(\sim 11 \mathrm{~kb})$ containing two independent T-DNA constructs (one with a SMG and one with the GOI) was used for co-transformation and successfully produced SMG-free transgenic sorghum [31].

\section{The twin T-DNA method}

As mentioned above, the super binary vectors are large and require an unwieldy in vivo homologous recombination method to assemble the constructs. Matthews et al. [29] developed an improved system called 'twin T-DNAs' to improve the shortcoming of 'super binary vectors.' In this system, a small so-called 'right-border/ left border' T-DNA 'twinning' insert was inserted into the polylinker of a standard binary vector in between a GOI and a SMG which were already in another set of left border (LB) and right border (RB) ( $L B-G O I-$ polylinker-SMG-RB). The resulting construct is $L B-G O I-$ $R B / L B-S M G-R B$, with two adjacent T-DNAs without any intervening sequence (Figure 1D). Using these two adjacent T-DNA constructs for co-transformation experiments, a co-transformation frequency of $66 \%$ was obtained, and $24 \%$ of the progeny segregated in the next generation to yield SMG-free transgenic barley. Taken together, approximately $16 \%$ useful independent co-insertion events among transformed lines were produced.

\section{One double right-border T-DNA on one vector method}

Instead of using multiple T-DNAs, a single T-DNA with a special design on the borders can also be used for co-transformation. To further extend the 'twin T-DNA' concept, Lu et al. developed a system called the double right-border (DRB) binary vector [32]. The DRB T- DNA construct contains the following components: RB1-SMG$R B 2-G O I-L B$. Two types of T-DNA inserts, one initiated from RB1: 'RB1-SMG-RB2-GOI-LB' and the other one from RB2: 'RB2-GOI-LB', were expected to be produced and integrated in the genome. The unlinked inserts can segregate away from each other in the subsequent generation and allow the selection of progeny with only the GOI (Figure 1E).

\section{One T-DNA (with SMG outside the borders) on one vector}

Another variant, described by Huang et al. [28], places the SMG outside the T-DNA borders, on the backbone of the binary vector, leaving only the GOI within the T-DNA. By taking advantage of the fact that the right border enhances the T-strand initiation while the left border enhances the T-strand termination [33], and that there exists the possibility of the left border readthrough, whereby the elongation of T-strand does not stop at the left border but includes the DNA fragment outside the left border [34], two of the inserts, RB-GOI-LB and 
RB-GOI-LB-SMG are expected to be produced and inserted into the genome of transgenic plants. By segregating away from each other, they successfully generated SMG-free transgenic maize plants (Figure 1F).

\section{Co-transformation using particle bombardment}

The co-bombardment method is analogous to the two-T-DNA Agrobacterium-mediated transformation method. Using co-bombardment, both plasmids with the SMG or GOI are coated onto the gold particles for shooting into plant tissue cells. Although unlinked integration of transgenes has been reported resulting in a few SMG-free plants, not many studies have produced marker-free plants using this system; none with high efficiency [35-38]. This is mostly because direct DNA transfer through bombardment frequently results in the insertion of multiple copies and rearrangement of the transgene into a genome or a single locus to form complex inserts [39]. The presence of multiple copies of transgenes, especially those arranged in inverted repeats, not only can induce transgene silencing $[40,41]$ but also complicates the segregation process. Recently, Prakash et al. have taken an improved strategy of co-bombardment by using "the linear essential DNA (not the whole plasmid)" and "limited amount of DNA (for bombardment)" approach to produce SMG-free transgenic corn [28]. This minimizes the shortcomings caused by using co-bombardment mentioned above. The linearized DNA cassettes were isolated from plasmids via appropriate restriction-enzyme digestions. Particle bombardment was performed with only $2.5 \mathrm{ng}$ of the SMG (nptII) cassette DNA and $15 \mathrm{ng}$ of the GOI cassette DNA per shot, amounts which are much lower than the 0.6-1 $\mu \mathrm{g}$ / shot suggested by the manufacturer of the Bio-Rad PDS1000 Biolistic Particle Delivery System. With this approach, 28 SMG-free maize plants were recovered from the progeny of $103 R_{0}$ plants containing both co-transformed constructs.

\section{Improved co-transformation strategies for SMG removal}

Although using co-transformation for SMG removal is not complicated, PCR screening can be time-intensive and tedious. Several strategies have been implemented to increase co-transformation efficiency. They include (1) the combined use of a negative selection marker with the positive selection marker, (2) the practice of 'transient' selection on the positive selection marker and (3) the use of androgenesis coupled with a co-transformation technique.

\section{Employment of positive-negative selection with co- transformation system}

In a co-transformation experiment, a positive SMG (such as nptII or bar gene) is used to co-transform with a GOI. The selected $\mathrm{T}_{0}$ plants (either with SMG-only or with both the SMG and GOI) are then allowed to set $T_{1}$ seeds to allow segregation to select the GOI-only transgenic plants. However, without the assistance of negative selection markers this practice requires a PCRbased screen on a large scale to isolate small portions of SMG-free/GOI-only transgenic plants from the segregating population [42]. Negative selection markers are used to optimize transformation efficiency; opposite to positive SMGs, they kill the transformed cells. This positivenegative selection method usually places a negative SMG next to a positive SMG in the construct [42-47]. The positive SMG is used for selection of the $T_{0}$ transgenic plants, and the negative SMG is then used to remove plants still harboring the 'negative SMG' cassette from the subsequent $T_{1}$ segregation population, and greatly reduce the transgenic plants for researchers to screen for the GOI-only transgenic plants (Figure 2).

The most widely used negative SMG for transgenic plant selection is the $\operatorname{cod} A$ gene from $E$. coli [42-46,48-50]. The $\operatorname{cod} A$ gene encodes cytosine deaminase, which converts the non-toxic 5-fluorocytosine (5-FC) into the toxic 5-fluorouracil (5-FU). Development of $\operatorname{cod} A$-expressing seedlings is strongly inhibited by germinating the seeds in the presence of 5-FC. Other negative SMGs such as iaaH, $\operatorname{argE}$ and cytochrome $P 450_{S U I}$ are also used to kill or inhibit the growth of the transgenic plants. The indole acetamide hydrolase $(\mathrm{iaaH})$ gene product converts naphthalene acetamide (NAM) to naphthaleneacetic acid (NAA), resulting in the inhibition of normal plant growth $[51,52]$. The Escherichia coli ornithine deacetylase gene $\arg E$ is an acetyl transferase that deacetylates inactive $\mathrm{N}$-acetyl phosphinothricin (N-acetyl-PPT), a chemical that is not toxic to plants, and produces phosphinothricin (PPT), the active ingredient of the Basta $^{\circledR}$ non-selective herbicide $[53,54]$. Bacterial cytochrome $P 450_{\text {SUI }}$ converts non-toxic pro-herbicide R4702 into cyto-toxic herbicide R4702 $[50,55,56]$. Most recently, a transcriptional activator protein gene $(\operatorname{Tr} A P)$ from Mungbean yellow mosaic virus (MYMV) was also used as a negative SMG in a positivenegative selection system to generate SMG-free tobacco plants [47].

\section{Transient positive selection of co-transformed plants}

Most marker-removing strategies in co-transformation system require two steps: first, the GOI construct and SMG construct are introduced into cells to obtain $T_{0}$ transgenic plants with proper positive selection; then the SMG is removed by genetic segregation in the $\mathrm{T}_{1}$ generation. If GOI and SMG could be separated early in the $\mathrm{T}_{0}$ generation, there would be a two-fold advantage: (1) faster breeding time, (2) obviating the segregation process to remove the SMG in the $T_{1}$ generation. This would be of special benefit for asexual-propagated plants that do not go through segregation. Transgenes transferred into plant cells are not necessarily stably integrated into the genome. In rare cases, an un-integrated 


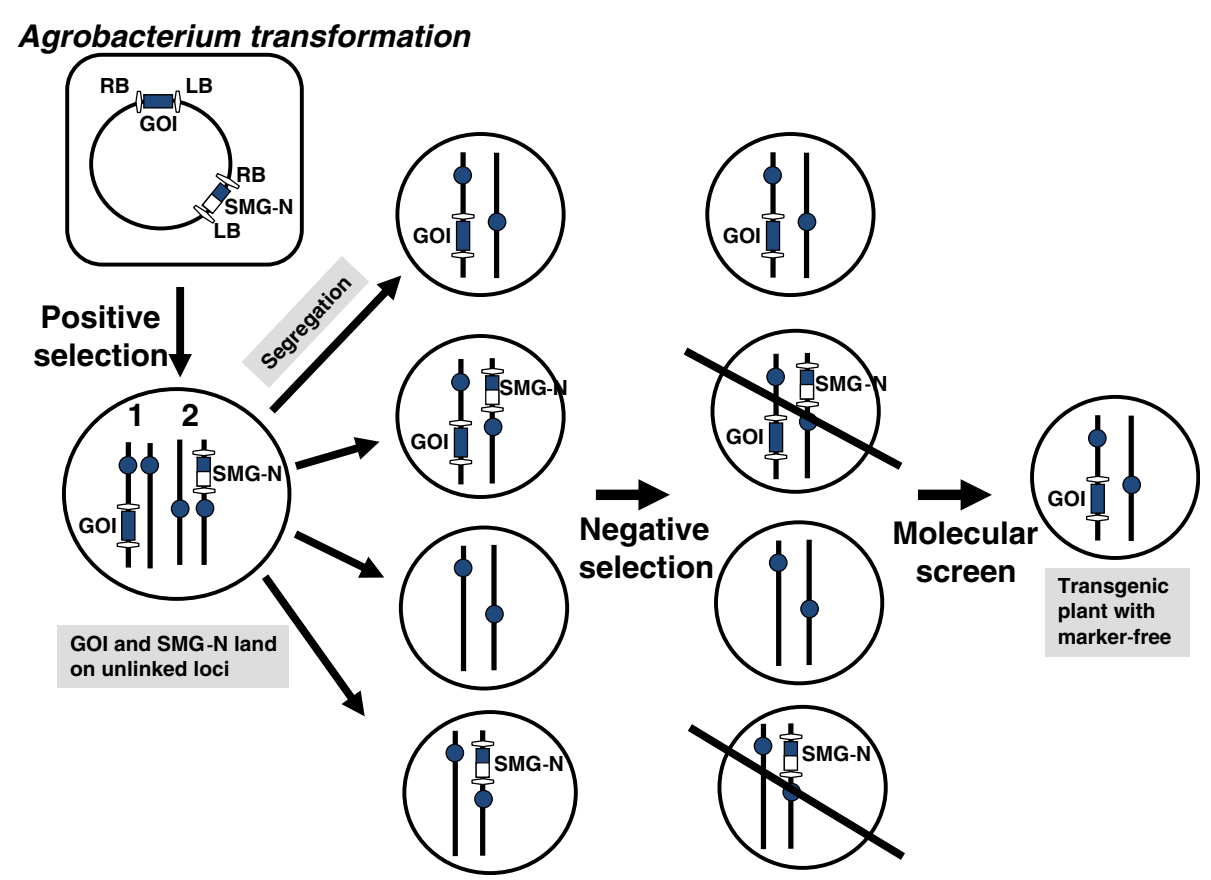

Figure 2 Positive-negative selection scheme in producing SMG-free transgenic plants. A negative selectable marker gene (' $\mathrm{N}$ ') is build next to a positive selectable marker gene (SMG), SMG-N, as depicted in the figure. After genetic transformation, explants are first selected with the positive selectable marker. Seeds of next generation are then selected with a negative selectable marker to remove $50 \%$ plants which still have SMG-N. PCR is then followed to screen marker-free transgenic plants. Abbreviations. RB: T-DNA right border, LB: T-DNA left border, GOI: gene of interest.

T-DNA (with SMG) and a stably integrated GOI may co-exist in some cells. With a short selection phase, those cells may survive on the select medium with the transient expression of the SMG. While performing cotransformation using a positive-negative marker selection, Ramana Rao and Veluthambi [47] recovered 4.4\% (5/114 plants) of GOI-only, SMG-free, transgenic plants in the $T_{0}$ generation with a 'transient' (2-4 weeks) period of positive selection. Dutt et al. used a transient positive-selection method to obtain SMG-free, GOI-only, transgenic grapevine from $\mathrm{T}_{0}$ generation [46].

\section{Androgenic segregation after co-transformation for marker free plants}

In androgenesis pollen development is arrested to force them towards a somatic developmental pathway. In vitro androgenesis can be achieved using microspores leading to the formation of haploid cells and plants either by direct embryogenesis or via callus formation [57]. The SMG-free, GOI-only transgenic plants can be obtained through androgenic segregation by anther culture after co-transformation. Subsequent to co-transformation with unlinked T-DNAs, anthers from the regenerated transgenic plants can be used for induction of androgenesis through anther culture. Since some haploid chromosomes can spontaneously divide and diploidize during anther culture, this practice could be used to produce genetically true-breeding, homozygous doubled-haploid (DH) and marker-free plants [58]. Li and his co-workers [59] have used the co-transformation and anther culture approach to rapidly generate SMG-free doubled-haploid transgenic rice in one year with an efficiency of $12.2 \%$.

\section{Transposon-based SMG removal}

Transposons are comprised by genetic elements that can "jump" around in the genome of an organism. The best characterized transposons are those of the $A c / D s$ family, which were first discovered in maize by Barbara McClintock when studying phenotypic markers of maize germplasm [60]. $A c$ and $D s$ are two related elements. $A c$, short for activator, encodes the enzyme transposase, while the $D s$, short for dissociation, is a deletion version of $A c$ element. Both elements share 11-bp terminal inverted repeat sequences (TIRs). Since the $A c$ element can produce a $102-\mathrm{kD}$ functional transposase to move itself around in the genome; it is termed autonomous. On the other hand, the $D s$ element requires $A c$ to produce transposase for transposition; therefore, considered nonautonomous. Approximately $200 \mathrm{bp}$ on each end of the element is necessary for transposition. Transposase binds to the hexamer motif AAACGG within these 200 base pairs. Excision of $A c / D s$ elements leaves a characteristic footprint (minor sequence changes) at the donor site. 
The Ac element has the ability to move to new locations within a genome, so the GOI or the SMG can be placed within the 'jumping' sequence and eventually being excised and re-insert into other locations in the genome. An example of a vector designed for this purpose is described in Figure 3A. The GOI cassette flanked by two terminal-inverted repeats of the maize $A c / D s$ transposon system was build next to an SMG and $A c$ transposase cassette. After the T-DNA is transferred into plants, the $A c / D s$ system becomes active. The encoded transposase recognizes the inverted repeat signals at both ends of the GOI and catalyze the relocation of the GOI in the genome. Once the GOI jumps away from the SMG in the genome and becomes genetically unlinked, segregation can result in GOI-only plants. Cotsaftis et al. [61] have used this approach to obtain insectresistance rice without an SMG. It is worth noting that the additional advantage of using a GOI re-positionmediated-by-transposon strategy is that a large population of transgenic lines with the target gene (GOI) can be generated for evaluation for position effects, which is very useful for species which are not amenable for efficient genetic transformation, such as wheat.

The SMG could also be placed in between the inverted repeat signals, instead of GOI (Figure 3B). It was found that about $10 \%$ of the $A c$ elements that are excised do not re-insert and therefore disappear from the genome or reinsert into a sister chromatid that is subsequently lost during somatic segregation. Ebinuma et al. [62] employed the Ac element to remove the isopentenyl transferase gene (ipt), which was used for visually distinguishing transgenic plants from non-transgenic plants by identifying the ipt "shooty" phenotype. In this study, a T-DNA was constructed to contain an $A c$ element linked to an SMG cassette (35S promoter-ipt gene-terminator) and a GOI cassette. When the $A c$ element transposed, the ipt gene transposed too and was subsequently removed, which resulted in a T-DNA that contained only the GOI cassette. Six months after infection, the researchers had obtained SMG-free transgenic tobacco plants - from which $A c$ had disappeared from $4.8 \%$ of the transgenic lines. If an excised element does not re-insert and simply disappears

A.

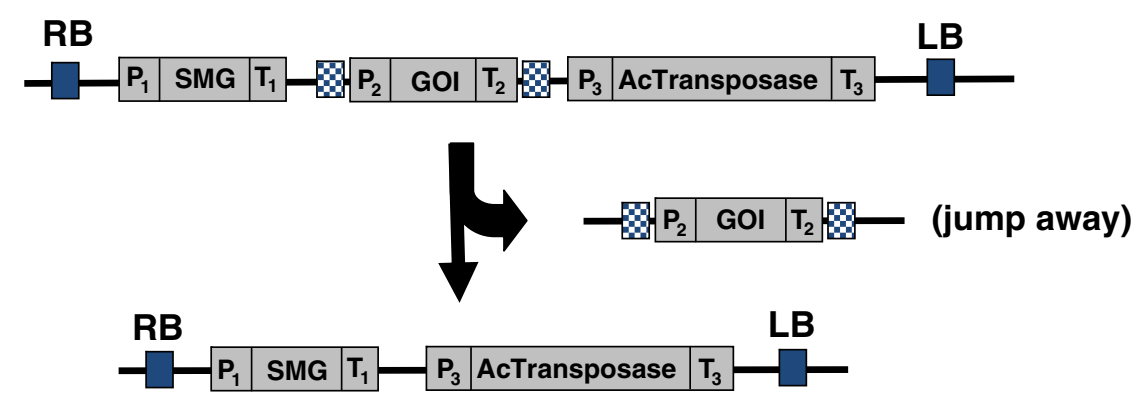

B.
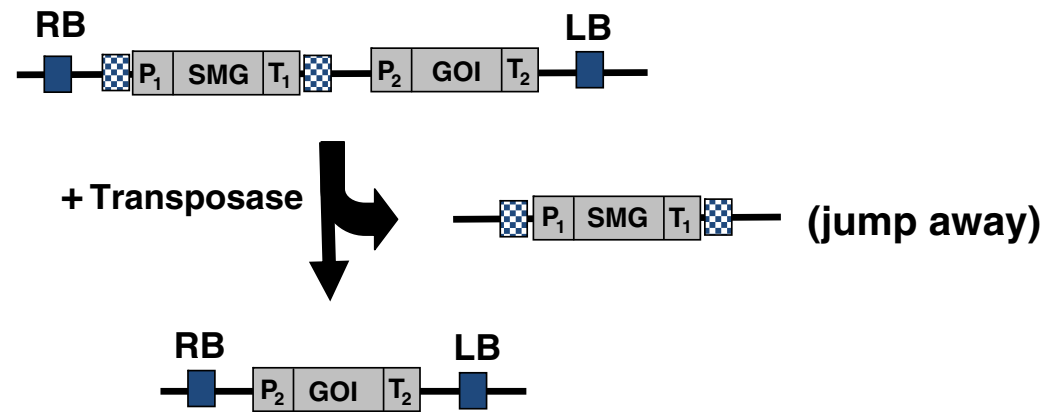

Figure 3 Strategy for using Ac transposon element to produce SMG-free transgenic plants. (A) T-DNA contains both the GOI (flanked by transposase-recognizing sites) and the transposase is transformed into plants. When the transposase is activated, the GOI cassette will be excised and insert into a different locus. If the GOI cassette lands at an unlinked locus, the SMG-free transgenic plants can be obtained after segregation in the subsequent generation. (B) T-DNA containing both the SMG (flanked by transposase-recognizing inverted repeat sequences) and the GOI is transformed into plants. When transposase activity is provided, the SMG cassette can move away and insert into a different locus. If the SMG and $\mathrm{GOI}$ cassettes land at an unlinked locus, the SMG-free transgenic plants can be obtained after genetic segregation in the sequential generation. Abbreviations. RB: T-DNA right border, LB: T-DNA left border, GOl: gene of interest, SMG: selectable marker gene. $P_{1}, P_{2}$ and $P_{3}$ : promoters, $T_{1}, T_{2}$ and $T_{3}$ : terminators. 
from the genome, the genetic segregation process is not needed. This would be a useful approach to produce asexually propagated plant species containing no SMG. More recently, an elegant study combined the piggyBac transposon system and the $\phi C 31$ site-specific recombination system to produce SMG-free transgenic lines and stabilized (demobilized) an unstable transgenic gene cassette by eliminating its 5 'end transposon TIR in fruit fly [63]. This approach can be useful for transposon-mutated plant lines.

\section{Site-specific recombination-mediated SMG removal}

Site-specific recombination systems have advanced in diversity and applications in recent years. Applications include SMG removal. Site-specific recombination systems are common in prokaryotes and lower eukaryotes such as yeast and serve various biological functions [64]. The recombinase protein catalyzes recombination of DNA between two recognition sites. The outcome of the recombination can be site-specific excision, integration, inversion or translocation depending on the position and the relative orientation of the two recognition sites on the DNA molecules (either linear or circular form), and the type of reaction is dependent on enzyme type. Cre-lox site-specific recombination system was the first to be used for SMG excision in tobacco $[65,66]$. Since then, many labs have successfully used Cre-lox or other later-identified site-specific recombination systems for SMG removal in plants (reviewed by Gidoni et al. [67]).
SMG removal using recombinase systems have proven effective. A common feature in these studies is the production of transgenic plants with a SMG flanked by two recombination sites oriented in the same direction. Upon expression of the corresponding recombinase, a site-specific recombination event excised the SMG residing between the recombination sites.

\section{Constitutive expression of a recombinase gene using plant hybridization or retransformation}

Initial studies using site-specific recombination systems to remove SMGs in plants used either a hybridization strategy, or a re-transformation strategy. For the hybridization strategy, the target plant is produced with a GOI and the SMG flanked by recognition sites (Figure 4A). The recombinase-expressing transgenic plant is hybridized with the target plant so that hybrid $F_{1}$ plants will have SMGs excised. $F_{1}$ plants containing both transgenes are used to screen for deletion events (in this case, SMG removal) (Figure 4B). Transgenic plants with recombination events are then backcrossed to wild type for obtaining offspring with germ line transmission of the final product of excision and absence of the recombinase gene. For the re-transformation strategy, after target line plants are produced, they are re-transformed with a recombinaseexpressing cassette (for which a different SMG is needed). The re-transformed lines are screened for the presence of the recombinase-expressing gene. Transgenic lines with the gene are allowed to set seeds, and plants derived from

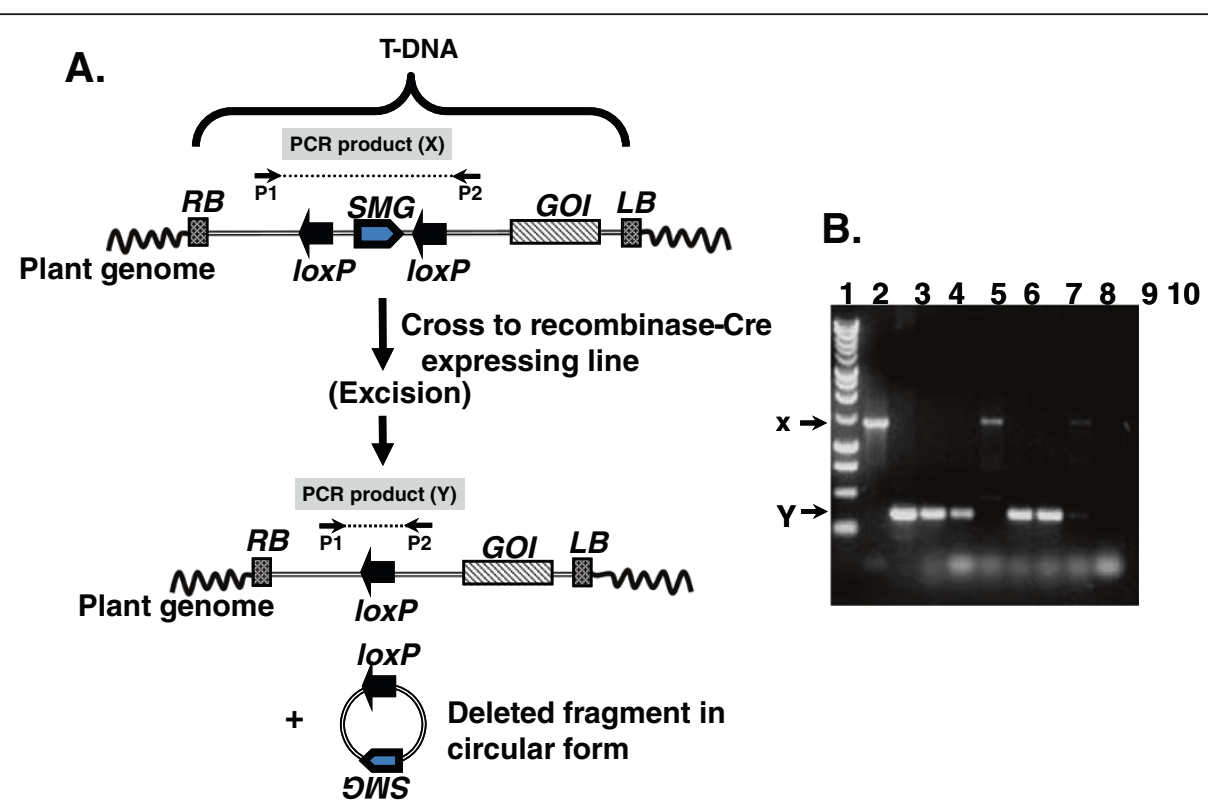

Figure 4 PCR screening of Cre-lox-mediated SMG excision events in plant genome. (A) Using primers P1 and P2 designed from outside the two loxP sites, PCR product ' $X$ ' (parental band) was amplified when no excision occur, while ' $Y$ ' band is produced when excision events occur. (B) Lane 1: DNA markers, lane 2: parental band (X), lane 3: positive control band (Y) (obtained from transient assay in bacterial cells), lanes 4-9: excision event detection, lane 10: no DNA. Abbreviations. RB: T-DNA right border, LB: T-DNA left border, GOI: gene of interest, SMG: selectable marker gene. 
these seeds are tested for germ line transmission of the SMG-excised, final transgenic product. The recombinase gene can then be removed from the SMG-free GOI lines by genetic segregation if the recombinase gene and GOI are not linked. Although marker-free transgenic crop plants have been produced using these two processes, there are disadvantages to each. The hybridization strategy is restricted to sexually propagated species. For trees, long generation times make crossing schemes impractical. On the other hand, the re-transformation method is lengthy and requires twice the exposure to tissue culture-hormonal conditions, which could increase mutagen risk. There are also reports that overexpression of the recombinase gene might cause abnormalities in the transgenic plants [68], but this could be a risk for all recombinase-based systems. To avoid recombinase-mediated off-effects, the recombinase could be expressed transiently, inducibly, developmentally, and it could also be engineered for auto-excision.

\section{Transient expression of the recombinase gene}

To deliver recombinase genes into plant cells for transient, high-level expression of recombinase proteins, without integration of the recombinase genes into the genome, plant virus vectors [69,70] and Agrobacterium T-DNA vectors [71] can serve as vehicles. Kopertekh et al. reported using a Potato Virus X (PVX)-based vector to transiently express the Cre recombinase gene to remove a SMG from transgenic Nicotiana benthamiana [69]. Kopertekh and Schiemann also reported using an agroinfiltration technique to perform Cre-mediated SMG removal in $N$. benthamiana [71]. The efficiency of obtaining the regenerants with the bar gene excised was 34\%. Among these $20 \%$ of the plants were caused by the expression of a stably integrated cre gene, whereas the remainder (14\%) resulted from transient cre gene expression. Particle bombardment has also been used. Srivastava et al. cobombarded a cre gene construct and an integration vector into maize callus containing the a target construct for site-specific integration [72]. They found that $60 \%$ of the single-copy-transgene-inserted plants lacked the recombinase gene, indicating that cre gene expression was transient.

\section{Induced expression of a recombinase gene}

In order to further control the excision process to remove the SMG at a certain time and avoid constant expression of recombinase genes, recombinase genes have been placed under the control of inducible promoters. These include heat shock inducible promoters [73] and chemical inducible promoters. By activating the promoters with inducers (heat or chemicals), the expression of the recombinase gene can be more tightly controlled, even though existing promoters used for this purpose typically lack regulatory precision. In one strategy, the SMG, the recombinase gene, and the GOI are cloned into a single construct. The recombinase gene under the control of an inducible promoter and the SMG are placed into a cassette flanked by two recombination sites oriented in the same direction, whereas the GOI is placed outside the region flanked by the recognition sites. After transformation and molecular analysis, the transgenic plants are treated with inducers for removal of SMG and recombinase (Figure 5). This strategy of using a heat shock inducible promoter to control timely expression of the recombinase gene has been applied to Arabidopsis [74], maize [75], tobacco [76], potato [77] and aspen [78] for site-specific recombination events.

A chemical-induced promoter was used for a recom binase-based SMG removal in Arabidopsis by Zuo et al. [79], wherein an estrogen-receptor-based transactivator XVE, for the bacterial repressor LexA (X), the acidic transactivating domain of VP16 (V), and the regulatory region of the human estrogen receptor (E) [80] and the Cre-lox system were used in combination. In transgenic plants, $\beta$-estradiol-activated XVE stimulated expression of the Cre protein under the control of the target promoter; this resulted in Cre-mediated sitespecific recombination events and deletion of the unnecessary DNA. The XVE system was also used in aspen with FLP-FRT system [81], in rice with Cre-lox system [82], in tomato with Cre-lox system to produce SMGfree transgenic plants $[83,84]$. In another system, Woo et al. reported auto-excision of SMG from transgenic tobacco via a stress-inducible FLP-FRT site-specific recombination system [85]. In this system, an oxidativestress-inducible promoter, a peroxidase (POD) promoter, was fused to the recombinase gene $f l p$. Hydrogen peroxide $\left(\mathrm{H}_{2} \mathrm{O}_{2}\right)$ was used to induce the recombinase gene, and the successful excision of SMGs via hydrogen peroxide $\left(\mathrm{H}_{2} \mathrm{O}_{2}\right)$-regulated site-specific recombination was observed.

Because heat-shock treatments and chemicals are required for recombinase activation for SMG deletion, these treatments may be limited to certain plant species and might complicate the transformation process [86]. Other problems associated with these inducible systems include low promoter induction, which can lead to incomplete transgene excision, and/or off-effects from leaky expression and unintended excision. Leakiness in promoter activity is common in transgenic plants and has been reported by several laboratories that used chemical- or heat shock-inducible promoters for recombinase gene expression [67]. Therefore, better promoters are needed to improve precision. In the absence of improved promoters a 'double-lock' method was employed by Joubès et al. [87] to tightly control a heat-shockinducible promoter (HSP18.2) and thus avoid premature activation of the inducible system. This strategy combines the use of Cre-lox site-specific recombination 
A.

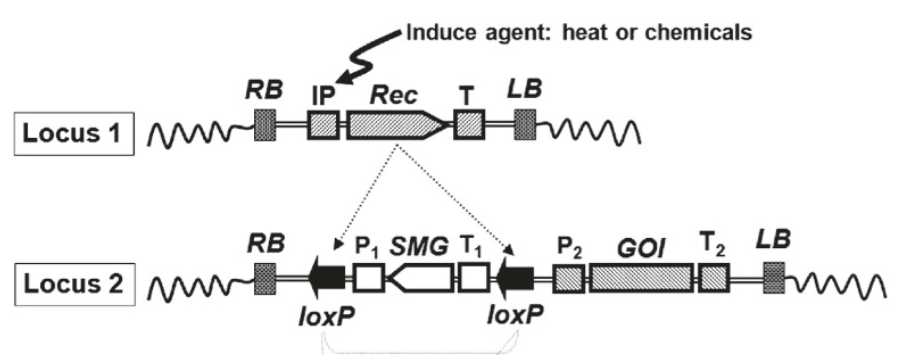

deleted fragment

Site-specific recombination
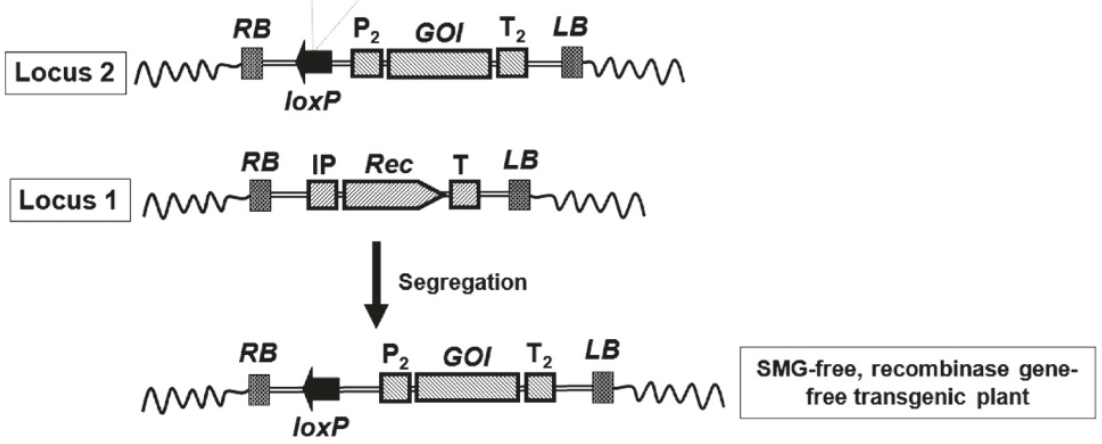

B.

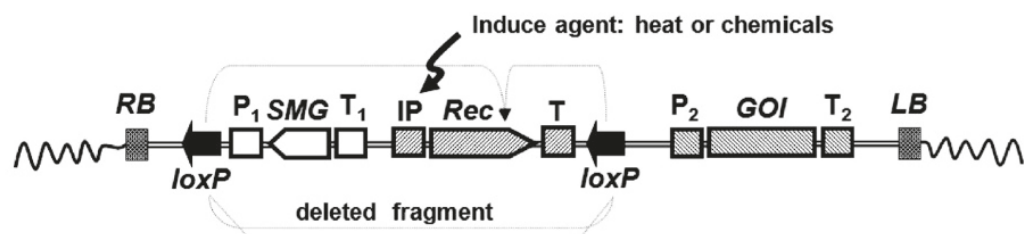

Site-specific recombination

SMG-free, recombinase genefree transgenic plant
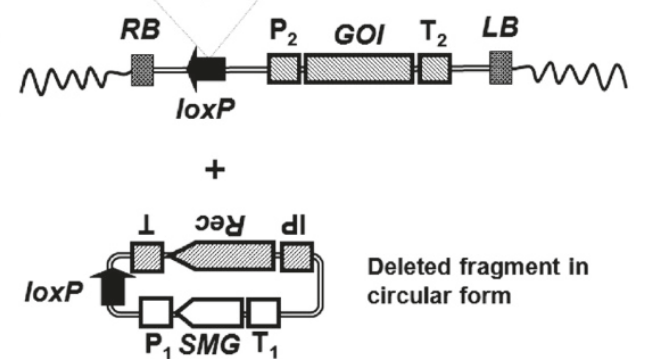

Deleted fragment in circular form

Figure 5 Strategy of using chemicals or heat to induce SMG-removal in transgenic plants. (A) The T-DNA contains an inducible promoter (IP) and a cre recombinase gene (Rec) that is transformed into a plant and reside at locus 1, while the second T-DNA cassette containing the SMG and $\mathrm{GOI}$ is transformed and integrates on locus 2. When the induce agent (heat or chemicals) is applied, Cre recombinase protein is produced and excises at the two loxP sites, which removes the $\mathrm{P}_{1}-\mathrm{SMG}_{\mathrm{T}} \mathrm{T}_{1}$ fragment. If locus 1 and locus 2 are unlinked, SMG-free transgenic plants can be obtained after segregation in the subsequent generation. (B) Autoexcision scheme. In the autoexcision strategy, the SMG and the cre recombinase gene [which uses an inducible promoter (IP)] are constructed within two loxP sites. Once the inducible promoter is activated, the whole unit within the two loxP sites is removed altogether. Abbreviations. RB: T-DNA right border, LB: T-DNA left border, GOl: gene of interest, SMG: selectable marker gene, IP: inducible promoter, $\mathrm{P}_{1}$ and $\mathrm{P}_{2}$ : promoters, $T, \mathrm{~T}_{1}$ and $\mathrm{T}_{2}$ : terminators. 
system and a mammalian glucocorticoid receptor (GR) for the tightly control on the transcription and translation levels. No deletion was detected when only chemical induction or only heat treatment was used, confirming the effectiveness of the double-lock approach.

Employing a strategy of using the constitutive promoter $35 \mathrm{~S}$ instead of inducible promoters to drive a recombinase for auto-excision of the SMG along with the recombinase gene at the same time has also been reported. Kondrák and colleagues [88] designed a transformation vector with an auto-excision cassette and one RB of T-DNA to successfully produce SMG and plasmid-backbone-free transgenic plants. However, since $35 \mathrm{~S}$ is a constitutive promoter, an intron was added inside the recombinase gene so that the recombinase gene would be inactive in E. coli or Agrobacterium cells, while providing recombinase activity when the intron was removed naturally in plant cells [89].

\section{Developmentally-programmed recombinase gene expression}

Although inducible promoters offer control over the timing of recombinase expression, tissue-specific promoters can be used to control excision at key development stages. Successful use of pollen-specific or other tissue-specific promoters to drive recombinase gene expression for SMG removal has been accomplished [86,90-94]. Mlynárová et al. used the tobacco microspore-specific NTM19 promoter to control cre expression for auto-excision in pollen [90]. The system was highly efficient with a failure rate of only 2 out of the 16,800 seeds (0.024\%), which were derived from the SMG-free tobacco pollen. Additionally, expression of the cre gene was tightly regulated; leakiness of the promoter was not observed. Verweire et al. also successfully demonstrated the use of Arabidopsis germline-specific promoters from the APETALA1 and SOLO DANCERS genes to achieve genetically programmed, Cre-recombinasemediated auto-excision for SMG-free plants [92]. More recently, Frédéric et al. evaluated seven different germlinerelated promoters for their suitability in regulating Cre expression in transgenic Arabidopsis [93]. Five out of the seven promoters, which varied in developmental stages and tissues were able to drive efficient Cre-mediated gene excision. The data also showed that use of these promoters resulted in lower variation in recombination frequency than previously reported for the $35 \mathrm{~S}$ promoter. These newly tested tissue-specific promoters provide an additional tool for the developmentally-programmed site-specific recombination-mediated SMG removal.

\section{Use of site-specific recombination for SMG removal in plastid transformation}

Genetic transformation of plastids has become an attractive alternative to nuclear gene transformation when very high recombinant protein levels (may represent up to $70 \%$ of leaf protein) and lack of transgene transmission via pollen (in many species) are desired. One drawback is that routine plastid transformation procedures in many major crops remains a challenge [95]. Site-specific recombination systems including Cre-lox and $\phi C 31-a t t$ were used to remove an SMG inserted into plastid genomes [96-98]. The approach generally takes two steps. First, the transplastomic plant target lines with loxPSMG-loxP or attP-SMG-attB construct is transformed into the plastid genomes using particle bombardment. Then the plastid-targeted recombinase gene engineered for expression in the nucleus is genetically transformed through Agrobacterium into the transplastomic plants. Expressed CRE or $\phi C 31$ recombinase proteins are then imported into chloroplasts where it excises the plastidintegrated SMG [99]. An alternate strategy used transient expression of the cre gene in transplastomic leaves by agroinfiltration, followed by plant regeneration. Approximately $10 \%$ of the regenerated plastid marker-free plants did not have the cre gene integrated in the nuclear genome [98].

\section{Use of meganucleases for SMG removal}

Meganucleases are homing endonucleases, a large family of DNA nucleases found in eukaryotes, bacteria and archae-bacteria [100]. Homing endonucleases typically are encoded by introns and inteins [101]. Similar to type II restriction enzymes, they cleave double-strand DNA. However, while type II restriction enzymes recognize short nucleotide sequences (3-8 bp), homing endonuclease recognize large target sequences $(12-40 \mathrm{bp})$, which are long enough to occur randomly only with a very low probability. For example, there is approximately one I-SceI cutting site every $7 \times 10^{10}$ bp $[102,103]$. The low probability of the presence of endogenous restriction sites decreases the risk of genome fractionation by the meganuclease upon expression.

I-SceI is one of the common-used homing endonucleases in research, encoded by the mobile group I intron of the large rRNA gene of Saccharomyces cerevisiae [104], which recognize and cleave a recognition sequence of 18 bases (TAGGGATAACAGGGTAAT). Early studies of the meganuclease I-SceI have illustrated how the cleavage activity of this protein initiates homologous recombination events in living cells and demonstrated the recombinogenic properties of chromosomal double-strand breaks or DSBs [103], and is now often used to induce gene targeting by promoting homologous recombination through creating sitespecific cleavage, a DSB [105]. In mammalian and plant cells, this approach has enhanced gene-targeting frequency by several orders of magnitude [106,107]. In addition to use in gene targeting, meganuclease engineering was also reported for transgene deletion. By using two I-SceI cutting 
sites flanking a SMG in a transgene construct, it is possible to induce double-strand breaks on both restriction sites to release the SMG upon the expression of I-SceI. The cut ends were re-joined through the non-homologous end-jointing (NHEJ) repair pathway, the predominant DSB repair pathway in plants (Figure 6) [108,109].

\section{SMG removal via intrachromosomal homologous recombination (ICR)}

The frequency of homologous recombination in flowering plants is very low. For example, according to a previous study, using ICR between two homologous sequences to induce transgene deletion in plants was investigated, and the ICR between closely linked repeated sequences occurs only at a frequency of approximately $10^{-6}-10^{-7}$ [110]. Various approaches have been applied to increase the frequency of homologous recombination for use in gene deletion or gene targeting studies. For example, Bertrand et al. [111] reported the spontaneous ICR frequency increased 5- to 20-fold from the original $1.2-1.5 \times 10^{-6}$ in mammalian cells expressing a mutant ${ }_{p} 53$ protein. In another example, the introduction of DSB by endonucleolytic cleavage (I-SceI) was also reported to increase the ICR frequency [107,112]. However, when Peter Meyer's group devised an ICR strategy, which was based on the recombination of the attP region of bacteriophage $\lambda$, but which did not require the presence of recombinase and other helper proteins, interestingly, high ICR frequency in transgenic plants was observed [113]. In this study, a construct was built to contain two 352-bp $\lambda$ phage attachment sites (or attP) as homologous repeats flanking a SMG. The construct was transformed into tobacco plants, and higher rates of ICR-induced SMG deletion were detected in different parts of two of eleven lines. There were no detectable deletion events in the other nine lines. They attributed this result to a transgene position effect. However, in parallel, the researchers observed that ICR is not always associated with precise homologous recombination between the two attP regions; larger deletions (in which regions outside the attP sequences were lost, as well) were also detected among the deletion events in the two lines. Illegitimate recombination was proposed as the underlying mechanism for the majority of the deletion events. The high frequency was proposed as that the T-DNAs were integrated into genomic DSBs and stimulate homologous recombination reaction [114], and the only known way to increase homologous recombination by several orders of magnitude- and simultaneously, illegitimate recombination events-is the presence of DSBs [115]. T-DNA can opportunistically exploit genome DSBs as suggested by Salomon and Puchta [116] and Chilton and Que [117].

\section{Utilization of zinc finger nuclease (ZFN) technology for SMG removal}

ZFNs, originally referred to as hybrid restriction enzymes, are fusions of zinc-finger-based DNA recognition modules to endonuclease domains from restriction enzymes [118]. These enzymes are engineered to contain a zinc finger DNA-binding domain (composed, typically, of 3-6 zinc fingers) and the nonsequence-specific DNA-

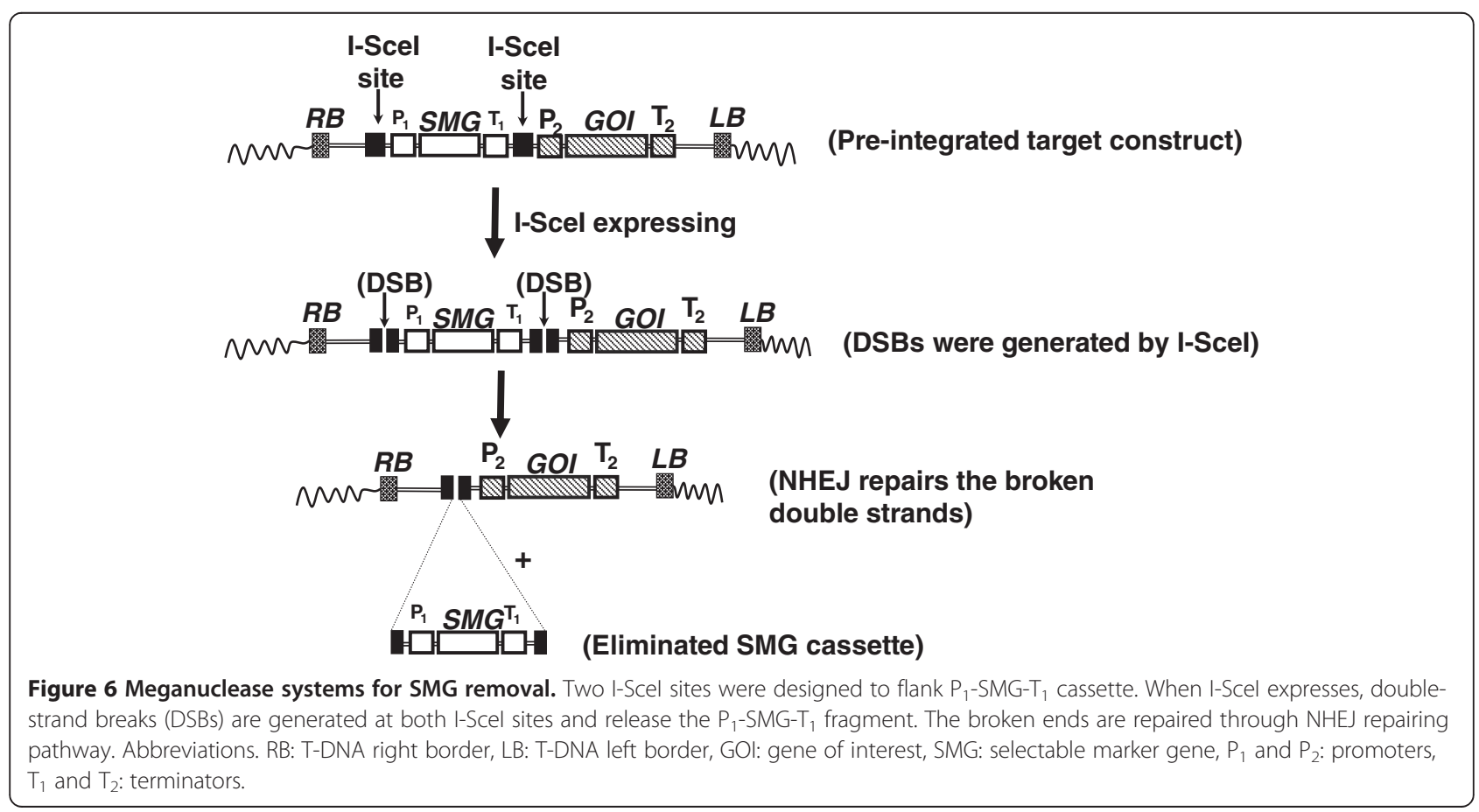


cleavage domain from the FokI type II restriction endonuclease (Fn domain) [115]. The cleavage domain of ZFNs must dimerize in order to cut DNA; therefore, efficient cleavage requires two zinc-finger-binding sites be located in close proximity to one another. Because the zinc finger domain can be engineered to recognize a wide range of novel DNA sequences, a specific ZFN can be designed, produced, introduced and directed to a specific genomic locus for cleavage.

ZFN technology has been widely used to introduce DSBs at endogenous loci in animal systems to generate allele mutations (a small deletion or insertion of bases at the break sites) and to achieve allele replacement to fix a defective allele, for example, through the NHEJ and homologous recombination repairing pathway, respectively (Figure 7). ZFNs were also deployed for gene excision in animal and plant cells. ZFNs can be used similar to meganuclease-mediated transgene deletion whereby, two concurrent DSBs introduced by ZFNs should be repaired such that the broken ends re-ligated by NHEJ, and the intervening chromosomal segment is excised (Table 1). Two recent reports have demonstrated the use of ZFNs to successfully eliminate DNA fragment in mammalian cells. Two ZFNs were used to target and cleave two different target sites and successfully eliminate the intervening dihydrofolate reductase gene and a 15-megabase chromosomal fragment from the Chinese hamster ovary cells and the human cells, respectively $[119,120]$.

Compared to applications in mammalian research, ZFNs have been used less-frequently for plant genome editing [121]. In plants, although the technology primarily focuses on introducing local genomic modification [122-126], ZFN technology was recently reported to use for plant SMG deletion. Petolino et al. demonstrated that a pre-integrated cassette containing GUS reporter gene flanked by two ZFN cleavage sites was deleted from a stably transformed plant by crossing it with a second plant expressing a corresponding ZFN gene [127]. The same scheme can also be used for SMG removal [127]. Moon et al. [94] also proposed this same ZFN method for SMG deletion in plant pollen.

The limitations and future prospects of existing methods for SMG removal in transgenic plants

Techniques to produce SMG-free transgenic plants have continued to undergo innovation, which is an indicator of the industry need. Another factor driving innovation is that each method we have discussed has limitations.

Using no selection is impractical in most species. There are too many escapes and latent Agrobacterium contamination that can confound the results obtained from the system which relies heavily on PCR selection

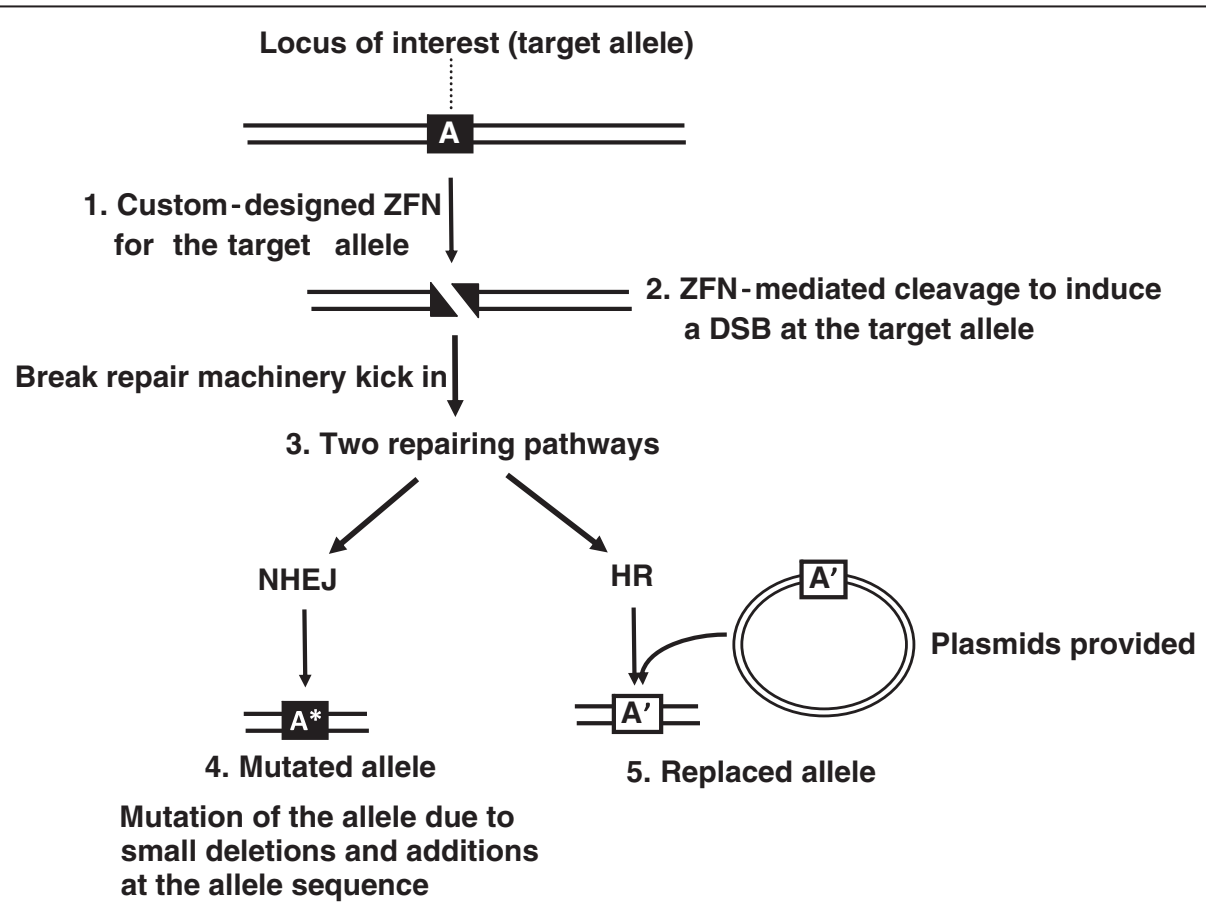

Figure 7 ZFN technology to modify an allele at a target locus. 1. Custom-designed ZFN is used to target the target allele ' $A$ '. 2. ZFN-mediated cleavage to induce a DSB at allele ' $A$ '. 3. The broken ends were repaired through endogenous repairing pathway. 4. If the broken ends are repaired through NHEJ pathway, a mutated allele ('A') will be generated due to deletions or additions. 5. If HR repairing pathway is used and plasmids with a 'replacement' allele ( $A$ ', which has partial homologous sequences to allele A) are provided, the allele at the target locus can be replaced to A'. 
Table 1 Summary of key features of DNA-modifying technologies that have been employed for removal of selectable marker genes from plants

\begin{tabular}{llll}
\hline System Name & Meganuclease & Site-specific recombinase & ZFN \\
\hline Enzyme involved & Homing nucleases & Site-specific recombinases & Zinc-finger fused Fokl nuclease \\
System examples & I-Scel & Cre-lox, phiC31-att & Custom-designed ZFNs \\
Recognition sites & Specific DNA sequence & Specific DNA sequence & Any endorgenous targeted DNA sequence \\
Pre-inserted target sites & Needed [random insertion] & Needed [random insertion] & Not needed [locus specific] \\
Reaction mode & Induce DSB and repair mechanism & Site-specific recombination & Induce DSB and repair mechanism \\
Product & Not-conserved [through NHEJ repair] & Conserved & Not-conserved [through NHEJ repair] \\
$\begin{array}{l}\text { Concerns of using this } \\
\text { technology }\end{array}$ & Natural existing sites in genomes & Pseudo sites in genomes & Low affinity of ZFN to target DNA \\
$\begin{array}{l}\text { Negative impacts from the } \\
\text { concerns above }\end{array}$ & Genome fractionation & Chromosome rearrangement or & Non-specific DSB induction at the \\
\hline
\end{tabular}

[128]. In addition, no selection can increase the number of chimeric transgenic plants recovered [25]. Therefore, simply not using SMGs for most agriculturally-important plant species will probably not be commercially viable.

At the other end of the spectrum, the co-transformation approach is probably the simplest method to obtain SMGfree transgenic plants. Many isolates of A. tumefaciens contain more than one T-DNA, and crown gall tumors often contain multiple T-DNAs [129]. Also, it is generally less tedious to construct a vector with only a GOI or SMG in each T-DNA. However, there are disadvantages to this approach. Success is tied with having an efficient transformation system, which is typically not the case for most elite crop cultivars. Also, if the two constructs are integrated into the same locus or closely linked loci, it could be nearly impossible to segregate them away from each other. This is especially true of the 'twin T-DNA' strategy where the two T-DNAs are physically linked to each other. Third, even with a relatively efficient cotransformation system, many putative transgenic plants must be screened, although this drawback can be addressed by the combined use of positive-negative selection systems. Finally, co-transformation-based SMG removal is typically applied on sexually propagated plants whose genomes undergo recombination and segregation, not to vegetatively propagated plants. However, a recent approach using transient positive selection coupled with long negative selection recovered a few SMG-free GOIonly transgenic plants at the $\mathrm{T}_{0}$ generation for vegetatively propagated plants, but it is not an efficient system [47].

A transposon-based approach to remove SMG away from GOI or remove GOI away from SMG is an attractive method, but it also has some drawbacks. The first is a transposon system must exist in the laboratory for the species of interest. In addition, transposon systems typically are not very precise and can take a long time for the repeated insertion-and-excision cycles to delete the SMG; the process itself can lead to mutations and increase the genomic instability in transgenic plants [130].

Although the meganuclease-based and ICR-based methods to eliminate SMG are achievable in planta, they have not yet been widely explored as other the methods above. The frequency of occurrence of meganuclease rarecutting sites in crop genomes is one concern from a non-target mutation perspective. Another concern is the induction of various sizes of deletions at the DSB location from DSB-induced NHEJ repairing process may truncate neighboring genes [116]. Using the ICR approach to remove SMG seems relatively simple, as no expression of a heterologous recombinase is required. It is especially attractive for vegetatively propagated crops because no segregation is required. However, because the mechanism of excision of SMG between the two attP sequences (bacteriophage $\lambda$ attP site in the published case) is not fully understood, the activity of using attP sequences as recombination substrates needs to be demonstrated in crop species. In addition, it would be interesting to explore if other attP-like sites from other site-specific recombination systems (such as in Bxb1-att) or the other bacteriophage $\lambda$ attachment site $a t t B$ can be used in this application.

An SMG can be eliminated from pre-integrating a GOI-ZFN cutting site-SMG-ZFN cutting site cassette upon the expression of a custom-designed ZFN. However the complicated design and intensive testing of the ZFN arrays might limit the scope of usage of this technology. In addition, the intellectual property rights for plant applications rest in one company. A better-studied site-specific recombination system could be used for the same purpose. Nevertheless, since ZFNs can be designed to bind and cleave a wide range of endogenous DNA sequences, it will be a powerful tool to generate gene mutation and endogenous chromosomal fragment deletion 
and might find other broad applications in basic research and biotechnology soon in the future [131].

The various site-specific recombination approaches to remove SMGs is most likely to be widely applicable. Numerous labs have successfully employed site-specific recombination to produce SMG-free transgenic plants including major crops [67]. The first Cre-lox systemmediated SMG-free commercial corn LY038 was also produced and approved for marketing [132]. Using sitespecific recombination systems to remove SMGs seems to be a promising approach. However, to broadly use this technology in agriculture in the future, some issues need to be addressed and further improvements of these systems may be needed.

\section{Recombinase-caused plant cell toxicity}

Recombinase expression can cause abnormal phenotypes in plants [68]. Similarly, undesired effects following the overexpression of site-specific recombinases in mammalian cells have been documented [133]. Naiche et al.[134] observed that Cre activity causes widespread apoptosis and lethal anemia during embryonic development, and Liu et al. [135] found that $\phi C 31$ integrase induces a DNA damage response and chromosomal rearrangements in human adult fibroblasts. To avoid overexpression of the recombinases, transient approaches to skip stable integration of recombinase genes could be one way around the problem.

\section{The fate of the excised SMG cassette}

The general consensus is that the excised SMG fragment, usually in circular form, will naturally be degraded in the cell. However, Srivastava et al. [136] reported that rare cases (4 out of 72 plants) of excised SMG fragment remains in the cells as an extra-chromosomal circular molecules for several generations in wheat. In this case, the excised SMG fragment which contained a bar resistant gene (they referred to it as the 'bar circle') was detected with Southern blot analysis even in the progeny of $F_{3}$ and $F_{4}$ generations without the presence of Cre gene. Furthermore, from their study, the bar circles might have undergone replication, thus these events would need to be screened against so that SMG fragments are not inherited to progeny and in food. A site-specific recombination system for plastid genetic transformation to remove a SMG [137] might be compromised if excised DNA circles could remain in the plastid genome, which can occur up to 10,000 copies per cell [138].

\section{The endogenous pseudo-sites and genome instability}

Cryptic recombination-sites or pseudo-sites are native DNA sequences that are partially identical to the sequence of native site-specific recombination sites and can serve as substrates for the activity of recombinases and cause unintended recombination. Cryptic sites were reported present in yeast, mammalian and plant genomes. In yeast studies, recombination with pseudosites occurred at a very low frequency [139]. However, conducted in the E. coli system, Calos's group discovered that the cloned pseudo-loxP sequences from the human or mouse genome could support Cre-mediated recombination at up to $100 \%$ of the efficiency of the native loxP site [140]. A human Factor IX (hFIX) gene was also reported permanently integrated into two pseudo-attP sites, whose sequence is partial identical to the native attP sequence, in the mouse genome mediated by $\phi C 31$ site-specific recombination system [141]. Pseudo-attB sites for site-specific recombination system A118 were also reported present in the human genome [142]. In plants, pseudo-loxP sites were reported present in the plastid genomes [96]. Some potential $\phi C 31$ attB or attP pseudo-sites are also identified in Arabidopsis [143]. Although researchers are suggesting that these pseudosites may be useful for providing an endogenous landing sites for site-specific integration of exogenous genes of interest [140], the presence of these pseudo-sites also pose a threat to generate aberrant chromosomes upon the expression of recombinases. The aberrant chromosomes can be generated from genomic excision, inversion or translocation through unintended recombination between these pseudo-sites. Chromosome translocation has been observed in the plant nuclear genome harboring two native loxP sites upon the expression of cre recombinase $[144,145]$. Unintended duplication of loxP or other recombination sites resulting from successive cycles of transformation (for gene stacking) and SMG elimination may cause intra- and inter-chromosomal rearrangements and lead to genome instability in the transgenic crop [146]. Also, Cre-mediated site-specific recombination, which caused unintended deletions between a native loxP site and a pseudo-loxP site in transgenic tobacco plastid genomes was observed [96]. Chromosomal re-arrangements were also observed in mouse spermatid cells (which had chronic high-level expression of a cre gene) and led to male sterility. One hypothesis was that the Cre-mediated genomic rearrangements occurred, perhaps at pseudo loxP sites within the mouse genome [147].

Next generation sequencing of crop genomes could reveal pseudo recognition sites, which would allow choosing the most appropriate recombination system by crop [148]. In addition, using a recombinase that has a very long recognition site, such as the CinH-RS2 system (110 bp for the RS2 site) [149] would likely have fewer off-effects from unintended DSBs in the plant genome since these recognition sites would be exceedingly rareto-absent in most plant genomes. Again, genomic sequencing will be informative in that regard. 
Needs for future research using site-specific recombination for SMG removal

Explore other novel site-specific recombination systems for plant transgenesis

There are more than 100 prokaryotic site-specific recombination systems are known to exist. So far, only a few systems have been explored and utilized for plant genome manipulation. Programs with combined use of efficient multiple site-specific recombination systems for multiple functions in plant genomes are useful $[150,151]$.

\section{Develop a system for comparison of relative recombination} activity among different site-specific recombination systems The right choice of one or multiple robust site-specific recombination systems is the most critical factor to effectively facilitate genomic manipulation in plants. By far, except for the widely-used Cre-lox, R-R, FLP-FRT site-specific recombination systems, several other sitespecific recombination systems were also reported for SMG removal in planta recently. They are ParA-MRS [152,153], фC31-att [143], Bxb1-att [154,155] and CinH-RS2 [149,153]. However, the results of recombination efficiency from each of those recombination systems were collected from different labs using different methods, species, and conditions. Thus, there is no direct comparison of the recombination efficiency among these systems. Recombination sites from different site-specific recombination systems should be built as a unit into a construct and inserted into the same genomic site for direct recombination-efficiency evaluation, thus avoiding genomic position effects in the comparisons. Multi-integrase recombination sites (FRT-attP $\left.P_{\phi \mathrm{C} 31}-a t t P_{\mathrm{R} 4}-a_{t t} P_{\mathrm{TP} 901-1}-a t t P_{\mathrm{Bxb} 1}\right)$ from FLP, $\phi C 31$, R4, TP901-1 and Bxb1 site-specific systems were built together to evaluate the relative sitespecific recombination activity (in this case, integration activity was measured) were reported in mammalian cells [156]. In the study, the actual efficacy of producing transgenic cells with the corresponding integrases has been measured. However, such a study has yet to be accomplished in plants. It would be useful if a quantitative system were developed in plants to evaluate the recombination efficiency of different site-specific recombination site by site.

\section{The importance of a nuclear localization signal (NLS)}

Since recombinase-mediated DNA recombination reactions occur in the nucleus of plant cells, nuclear targeting of prokaryotic-originated recombinases might vary in excision efficiency. The $38-\mathrm{kDa}$ Cre protein from the most efficient Cre-lox system used for eukaryotic genome manipulation has been assumed to readily diffuse into the nucleus owing to its small size. However, researchers have now identified nuclear targeting determinants, which resemble eukaryotic nuclear localization signals, and these have been found to affect targeting to the nucleus [157]. Cre protein is one of the few prokaryotic proteins that have been shown to carry these NLSlike determinants. Adding an NLS to the recombinases have improved the efficiency of recombinase nuclear targeting and recombination efficiency. Cre-NLS and $\phi C 31-N L S$ (a NLS fused to the recombinase), were both reported to increase the efficiency of recombination in mammalian cells $[158,159]$.

\section{The importance of 'codon usage' (codon optimization)}

Since most of the site-specific recombination systems are from prokaryotic organisms, plant-codon optimization should increase plant expression of recombinases. In the animal kingdom, codon-optimized $\phi \mathrm{C} 31$ has reported to increase the recombination efficiency (site-specific integration in this case) from $40 \%$ to $69 \%$ in Drosophila [160]. Raymond and Soriano also reported that the mouse codon-optimized FLP and $\phi C 31$ recombinases, FLPo and $\phi C 31 \mathrm{o}$, improved recombination efficiency to similar levels to that of Cre, which is the most efficient sitespecific recombination system to mediate DNA recombination in vitro and in vivo [161]. Most recently, a wild type FLP (FLPwt) developed for chromosomal engineering in mammalian cells, a thermostable FLP mutant (FLPe) and the mouse codon-optimized FLP (FLPo) were used for comparison of their recombination efficiency to delete a SMG in the monocot species rice and onion $[151,162]$. They found that the FLPe resulted in efficient SMG excision with the relative efficiency approaching $100 \%$ in the rice while the FLPwt is ineffective in excising the SMG [151]. On the other hand, the FLPo was reported to yield similar recombination efficiency to that of Cre using a transient assay in onion cells [162]. The codon-optimized version of $\mathrm{CinH}$ recombinase, $\mathrm{CinHo}$, was successfully used to efficiently remove SMG in tobacco pollen by using pollen-specific promoters [149]. However, direct comparison of recombination ability between the wild type $\mathrm{CinH}$ and CinHo was not reported. Codon-optimization is worthy to be studied for improving site-specific recombination performance in plants.

\section{Use of uni-directional site-specific recombination systems}

In terms of reaction mode, there are two types of recombinases: uni-directional and bi-directional. Cre, FLP and $\mathrm{R}$ also called bi-directional recombinases because the recombination reactions (co-integration and excision) are fully and freely reversible. This occurs because their two recombination sites have identical sequence. For example, the product of the hybrid site derived from the recombination of the two loxP sites has the same sequence of the two loxP site and can be used as a substrate of Cre recombinase again. Therefore, this reversibility could re-integrate an SMG even though deletion reaction is kinetically favored. $\phi \mathrm{C} 31$ and $\mathrm{Bxb} 1$ are 
examples of uni-directional site-specific recombination system. Once hybrid sites are generated from an attB site and an attP site, the subsequent attL and attR sites differ and cannot serve as substrates for recombination anymore. This means once the SMG is excised, they are not able to re-insert into the genome.

\section{Implement site-specific recombination approaches into ZFN technology}

As described earlier, the SMG in a cassette can be eliminated from the genomes either by meganuclease-, by site-specific recombination system-, or by ZFN-mediated approaches. However, those SMG and GOI cassettes were all randomly pre-integrated beforehand, and because the insertion of GOI in the genome is random, subsequent screening for suitable GOI-expressing lines is needed because of position effects. In contrast, targeted insertion into an endogenous genomic locus of interest is attractive for genome manipulation, including allele mutation, allele replacement and gene stacking. Transgene integration into the same chromosome location can produce alleles that express at a predictable level as well [163]. Targeted genomic insertion also improves the qualitative and quantitative functional comparison of similar transgenes [164].
As mentioned earlier, one of the most unique characteristics of ZFN technology is that a DSB at a specific locus can be induced through ZFN-mediated cleavage in vivo and mutate the allele by NHEJ or replace the original allele with researcher-designed donor DNA sequence by homologous recombination (HR) repairing machinery. Therefore, GOI, SMG and site-specific recombination system components can be built on a same plasmid and inserted into the locus of interest by custom-designed ZFN initially, then site-specific recombination system can be used later to remove the unwanted DNA fragment (ex. SMG or integrated gene) or adding genes (gene stacking) (Figure 8). The GOI could be a functional allele used to replace an endogenous defective allele or a gene used to disrupt a functional allele [122,123]. Through ZFN-induced homologous recombination, the GOI-lox-SMG-lox can be integrated into the locus of interest. The SMG assists researchers to select the integration cell lines and can be removed later by a site-specific recombination system. Using an SMG gene, such as puro $^{R}$ or $h y g^{R}$, to assist the screening of transgenic clones generated by ZFNmediated gene targeting has been reported in human cells $[165,166]$. Alternatively, a site-specific recombination site, such as a $\phi C 31$ attP site, can be brought into the locus of interest and later used for gene stacking

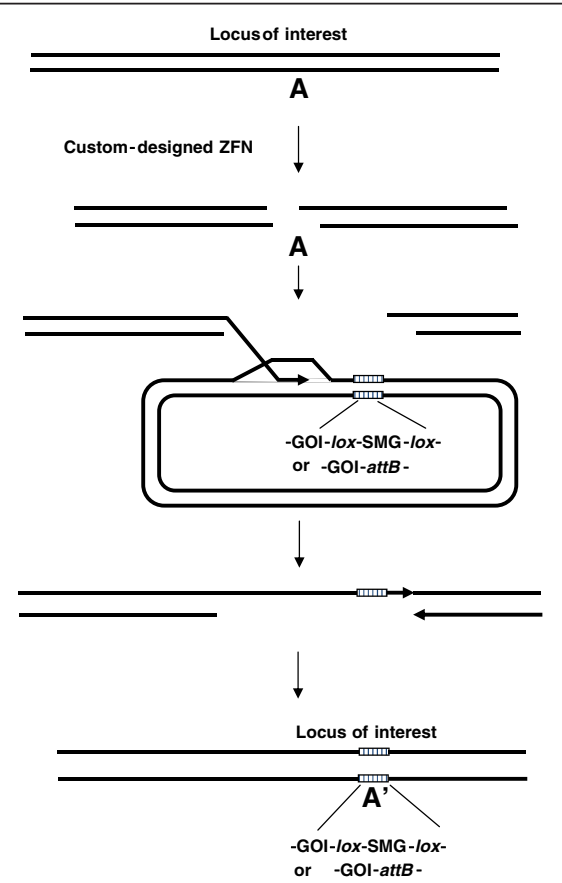

Undamaged double - stranded DNA

with a locusof interest (allele A)

ZFN-induced DSB within allele A

(Homology-directed repair)

Exogenous donor DNA carrying a GOI and a SMG cassette (or a GOI and a SSR recombination attB site) flanked by homologous sequences of the allele $A$ is used as template

Repairing of original DNA strands

Conversion of DNA sequence from A to $A^{\prime}$ at the locusof interest

Figure 8 Usage of ZFN technology to bring the site-specific recombination tool to a locus of interest for future use. As described in Figure 7, a DSB can be induced at an allele in a locus of interest by a custom-designed ZFN and repaired through HR pathway. This in turn can introduce a GOI-lox-SMG-lox or GOI-attB construct, for example, into the locus. The SMG can be deleted through recombinase-mediated sitespecific deletion. In the second case, the attB site can be used for transgene-stacking at this locus of interest. Abbreviations. GOl: gene of interest, SMG: selectable marker gene, lox: loxP site of Cre-lox site-specific recombination system. 
through $a t t P \times a t t B$ sites recombination. In this case, a plasmid contains a $\phi C 31$ attB site and a chosen GOI for stacking need to be provided [167]. Site-specific recombination systems are user-friendly molecular tools for eukaryotic cell genome editing without the complicated design and testing of ZFN arrays in ZFN technology. An approach of combining ZFNs for initial targeting of the site-specific recombination system to a locus of interest and subsequent use of site-specific recombination system for genome editing and SMG removal should be welcomed by many researchers.

\section{The possible use of TALENs for marker gene removal}

Transcription activation-like effector (TALE) proteins are produced by the plant pathogen Xanthomonas, and TALE family members are targeted to key plant genes [168]. In plants, TALEs localize to the nucleus and bind to target promoter region to trigger the expression of plant genes [169]. Recently, by taking advantage of their specific DNA binding properties, researchers fused the restriction domain of FokI nuclease to these TALEs to create TALEFokI nuclease (TALEN) hybrid proteins [170] and use them for biotechnological application such as gene targeting (reviewed by Scholze and Boch [171]). TALENs have used to successfully knockout genes in fish and mammals (rats and human) [172-174]. TALENs have been used to knockout target genes in plants, such as the ADH1 gene in Arabidopsis thaliana protoplasts [174], and used to produce disease-resistant rice [175]. Similar to ZFN technology, TALENs cause DNA double strand breakage (DSB) at a specific locus. As the result, the broken DNA is repaired through homologous recombination (HR) or NHEJ repairing pathways. Two identical sets of TALEN-binding sequences can be designed to flank a SMG in a transformation vector. After expression of TALEN, DSB will be induced at both TALEN-binding sequences and release the SMG (Figure 9). This strategy can be devised for maker-free transgenic plant production, or native chromosome fragment removal.

\section{Conclusions and perspectives}

Genetic transformation is an important technology for biology fundamental research and for engineering transgenic organisms, including plants. SMGs have been very useful to enable plant transformation, yet there are a number of regulatory concerns of retaining SMGs in commercialized transgenic plants, leading us to conclude that ideally, the SMG should be removed after transformation. The regulatory concerns seem to focus on horizontal gene transfer of bacterially-derived SMGs from transgenic plants to bacteria. This could be obviated with SMGs derived from plants such as the $\mathrm{ABC}$ transporter from Arabidopsis that confers kanamycin resistance [176]. It is a very large gene with plant-codon-optimization that would likely not be horizontally transferred to bacteria, and even if it would be, it has proven to be not very effective as a resistance gene in bacteria [177], and thus, would likely not be selected. Innovation for SMG removal will continue, and we shall, no doubt, see improvements in existing systems and new technologies such as TALENs be

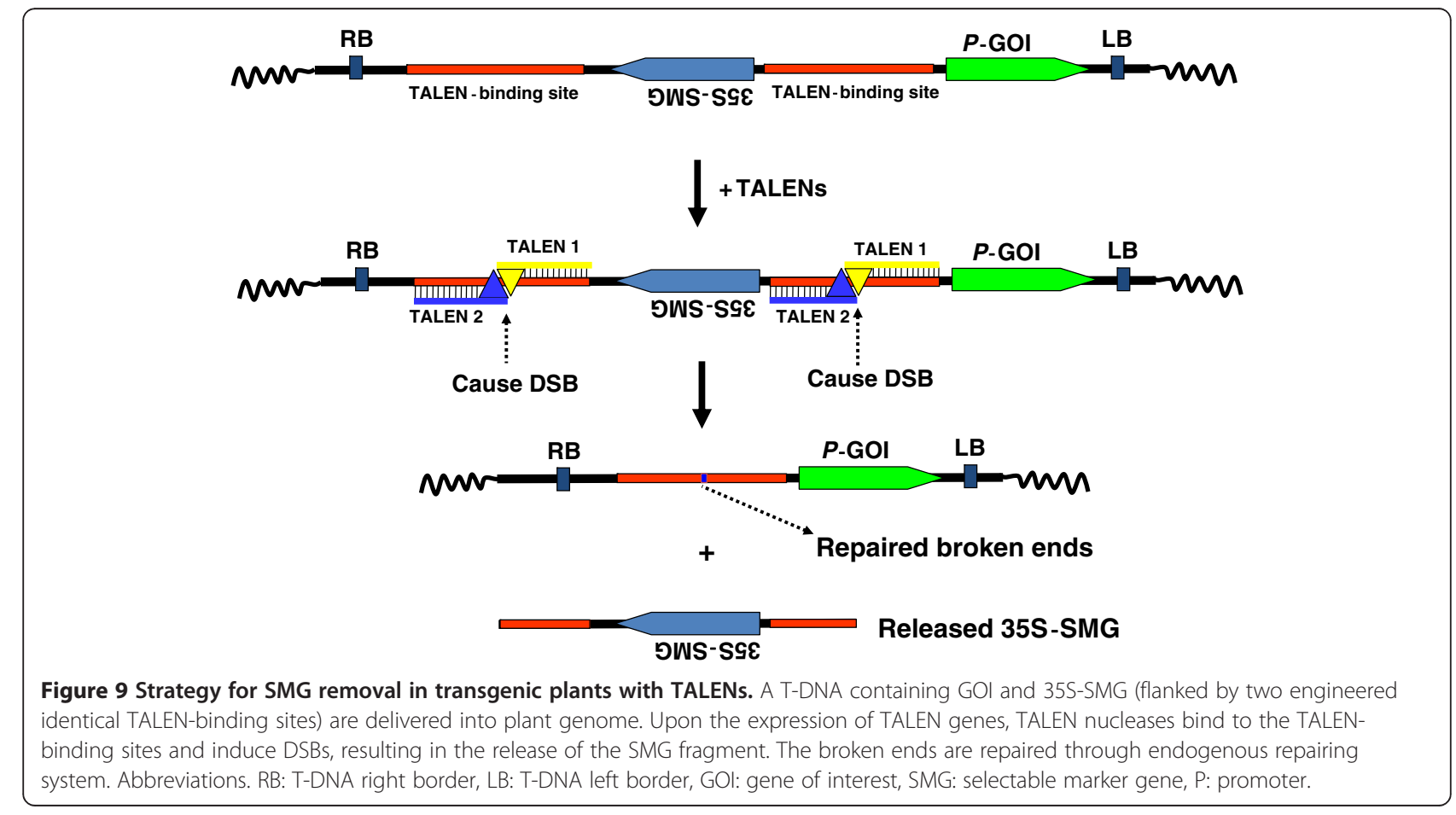


configured for this purpose. Of particular importance is precision and robustness of removal without unintended consequences. Certainly, using the least amount of DNA possible is important for intellectual property and government regulatory concerns. Efficient systems that can be deployed in a multitude of crop systems should have the most value.

\section{Abbreviations}

SMG: Selectable marker gene; GOI: Gene of interest; LoxP: Locus of crossingover P1; Cre: Causes recombination recombinase; HR: Homologous recombination; RB: Right border of T-DNA; LB: Left border of T-DNA; ICR: Intra-chromosomal recombination; DH: Double haploid; TIR: Terminal inverted repeat; PVX: Potato virus X; ZFN: Zinc finger nuclease; GR: Glucocorticoid receptor; NHEJ: Non homologous end joining; ptDNA: Plastid DNA; hFIX: Human, Factor IX; attB: Bacterial attachment site; attP: Phage attachment site; NLS: Nuclear localization signal; codA: Cytosine deaminase gene; 5-FC: 5-fluorocytosine; 5-FU: 5-fluorouraci; iaaH: Indole acetamide hydrolase gene; NAM: Naphthalene acetamide; NAA: Naphthaleneacetic acid; PPT: Phophinothricin; MYMV: Mungbean yellow mosaic virus; NPTII: Neomycin phosphotransferase; PCR: Polymerase chain reaction; Bar: Bialaphos resistance; T-DNA: Transfer DNA: TrAP: Transcriptional activator protein gene.
\end{abstract}

\section{Competing interests}

The authors declare that they have no competing interests.

\section{Authors' contributions}

YYY drafted the original manuscript and YYY and CNS substantially contributed to the content of the paper. All authors read and approved the final manuscript.

\section{Acknowledgments}

The authors would like to thank Robert Blanvillain for his careful reading of the manuscript and his suggestions and anonymous reviewers. We thank the NIFA Biotechnology Risk Assessment Grants program for support to CNS.

\section{Author details}

'Department of Natural Sciences, Northeastern State University, Broken Arrow, OK 74014, USA. ${ }^{2}$ Department of Plant Sciences, University of Tennessee, Knoxville, TN 37996, USA.

Received: 25 September 2012 Accepted: 5 March 2013 Published: 23 April 2013

\section{References}

1. Cohen SN, Chang ACY, Boyer HW, Helling RB: Construction of biologically functional bacterial plasmids in vitro. Proc Natl Acad Sci USA 1973, 70:3240-3244

2. Herrera-Estrella L, Depicker A, van Montagu M, Schell J: Expression of chimaeric genes transfered into plant cells using a Ti-plasmid-derived vector. Nature 1983, 303:209-213.

3. Bevan MW, Flavell RB, Chilton MD: A chimaeric antibiotic resistance gene as a selectable marker for plant cell transformation. Nature 1983, 304:184-187.

4. Fraley RT, Rogers SG, Horsch RB, Sanders PR, Flick JS, Adams SP, Bittner ML, Brand LA, Fink CL, Fry JS, Galluppi GR, Goldberg SB, Hoffmann NL, Woo SC: Expression of bacterial genes in plant cells. Proc Natl Acad Sci USA 1983, 80:4803-4807.

5. Murai N, Kemp JD, Sutton DW, Murray MG, Slightom JL, Merlo DJ, Reichert NA, Sengupta-Gopalan C, Stock CA, Barker RF, Hall TC: Phaseolin gene from bean is expressed after transfer to sunflower via tumor-inducing plasmid vectors. Science 1983, 222:476-482.

6. Farre G, Ramessar K, Twyman RM, Capell T, Christou P: The humanitarian impact of plant biotechnology: recent breakthroughs vs bottlenecks for adoption. Curr Opin Plant Biol 2010, 13:219-225.

7. Miki B, McHugh S: Selectable marker genes in transgenic plants: applications, alternatives and biosafety. J Biotechnol 2004, 107:193-232.

8. Mason P, Braun L, Warwick SI, Zhu B, Stewart CN Jr: Transgenic Bt-producing Brassica napus: Plutella xylostella selection pressure and fitness of weedy relatives. Environ Biosafety Res 2003, 2:263-276.
9. Kwit C, Moon HS, Warwick SI, Stewart CN Jr: Transgene introgression in, crop relatives: molecular evidence and mitigation strategies. Trends Biotechnol 2011, 29:284-293.

10. Ellstrand NC, Marshall DL: Interpopulation gene flow by pollen in wild radish, Raphanus sativus. Am Nat 1985, 126:606-616.

11. Warwick SI, Simard MJ, Légère A, Beckie HJ, Braun L, Zhu B, Mason P, Séguin-Swartz G, Stewart CN: Hybridization between transgenic Brassica napus L. and its wild relatives: Brassica rapa L., Raphanus raphanistrum L., Sinapis arvensis L., and Erucastrum gallicum (Willd.) O.E, Schulz. Theor Appl Genet 2003, 107:528-539.

12. Londo JP, Bautista NS, Sagers CL, Lee EH, Watrud LS: Glyphosate drift promotes changes in fitness and transgene gene flow in canola (Brassica napus) and hybrids. Ann Bot-London 2010, 106:957-965.

13. Fuchs RL, Ream JE, Hammond BG, Naylor MW, Leimgruber RM, Berberich SA: Safety assessment of the neomycin phosphotransferase II (NPTII) protein. Nat Biotechnol 1993, 11:1543-1547.

14. Rong J, Lu BR, Song Z, Su J, Snow AA, Zhang X, Sun S, Chen R, Wang F: Dramatic reduction of crop-to-crop gene flow within a short distance from transgenic rice fields. New Phytol 2007, 173:346-353.

15. Sugita $K$, Matsunaga $E$, Kasahara $T$, Ebinuma $H$ : Transgene stacking in plants in the absence of sexual crossing. Mol Breed 2000, 6:529-536.

16. RamanaRao MV, Parameswari C, Sripriya R, Veluthambi K: Transgene stacking and marker elimination in transgenic rice by sequential Agrobacterium-mediated co-transformation with the same selectable marker gene. Plant Cell Rep 2011, 30:1241-1252

17. Abuin A, Bradley A: Recycling selectable markers in mouse embryonic stem cells. Mol Cell Biol 1996, 16:1851-1856

18. Steiger MG, Vitikainen M, Uskonen P, Brunner K, Adam G, Pakula T, Penttilä M, Saloheimo M, Mach RL, Mach-Aigner AR: Transformation system for Hypocrea jecorina (Trichoderma reesei) that favors homologous integration and employs reusable bidirectionally selectable markers. Appl Environ Microbio/ 2011, 77:114-121.

19. Khan MS, Maliga P: Fluorescent antibiotic resistance marker to track plastid transformation in higher plants. Nat Biotechnol 1999, 17:910-915.

20. Urbanski WM, Condie BG: Textpresso site-specific recombinases: a textmining server for the recombinase literature including Cre mice and conditional alleles. Genesis 2009, 47:842-846.

21. Ow DW: GM Maize from site-specific recombination technology, what next? Curr Opin Biotechnol 2007, 18:115-120.

22. De Vetten N, Wolters AM, Raemakers $K$, van der Meer I, ter Stege R, Heeres E, Heeres $P$, Visser R: A transformation method for obtaining marker-free plants of a cross-pollinating and vegetatively propagated crop. Nat Biotechnol 2003, 21:439-442.

23. Holme IB, Brinch-Pedersen $\mathrm{H}$, Lange M, Holm PB: Transformation of barley (Hordeum vulgare L.) by Agrobacterium tumefaciens infection of in vitro cultured ovules. Plant Cell Rep 2006, 25:1325-1335.

24. Kim MS, Kim HS, Kim HN, Kim YS, Baek KH, Park YI, Joung H, Jeon JH: Growth and tuberization of transgenic potato plants expressing sense and antisense sequences of $\mathrm{Cu} / \mathrm{Zn}$ superoxide dismutase from lily chloroplasts. J Plant Biol 2007, 50:490-495.

25. Li B, Xie C, Qiu H: Production of selectable marker-free transgenic tobacco plants using a non-selection approach: chimerism or escape, transgene inheritance, and efficiency. Plant Cell Rep 2009, 28:373-386.

26. De Block M, Debrouwer D: Two T-DNA's co-transformed into Brassica napus by a double Agrobacterium tumefaciens infection are mainly integrated at the same locus. Theor App/ Genet 1991, 82:257-263.

27. Komari $T$, Hiei $Y$, Saito $Y$, Murai N, Kumashiro T: Vectors carrying two separate T-DNAs for co-transformation of higher plants mediated by Agrobacterium tumefaciens and segregation of transformants free from selection markers. Plant J 1996, 10:165-174.

28. Prakash NS, Bhojaraja R, Shivbachan SK, Priya GGH, Nagraj TK, Prasad V, Babu VS, Jayaprakash TL, Dasgupta S, Spencer TM, Boddupalli RS: Marker-free transgenic corn plant production through co-bombardment. Plant Cell Rep 2009, 28:1655-1668

29. Matthews PR, Wang MB, Waterhouse PM, Thornton S, Fieg SJ, Gubler F, Jacobsen JV: Marker gene elimination from transgenic barley, using cotransformation with adjacent 'twin T-DNAs' on a standard Agrobacterium transformation vector. Mol Breeding 2001, 7:195-202.

30. Zhou HY, Chen SB, Li XG, Xiao GF, Wei XL, Zhu Z: Generating marker-free transgenic tobacco plants by Agrobacterium-mediated transformation with double T-DNA binary vector. Acta Botanica Sinica 2003, 45:1 103-1108. 
31. Lu L, Wu X, Yin X, Morrand J, Chen X, Folk WR, Zhang ZJ: Development of marker-free transgenic sorghum [Sorghum bicolor (L.) Moench] using standard binary vectors with bar as a selectable marker. Plant Cell Tiss Organ Cult 2009, 99:97-108.

32. Lu HJ, Zhou XR, Gong ZX, Upadhyaya NM: Generation of selectable marker-free transgenic rice using double right-border (DRB) binary vectors. Aust J Plant Physiol 2001, 28:241-248.

33. Wang K, Genetello C, Van Montagu M, Zambryski P: Sequence context of the T-DNA border repeat elements determines its relative activity during T-DNA transfer to plant cells. Mol Gen Genet 1987, 210:338-346.

34. De Buck S, De Wilde C, Van Montagu M, Depicker A: T-DNA vector backbone sequences are frequently integrated into the genome of transgenic plants obtained by Agrobacterium-mediated transformation. Mol Breeding 2000, 6:459-468.

35. Rooke L, Steele SH, Barcelo P, Shewry PR, Lazzeri PA: Transgene inheritance, segregation and expression in bread wheat. Euphytica 2003, 129:301-309.

36. Tu J, Datta K, Oliva N, Zhang G, Xu C, Khush GS, Zhang Q, Datta SK: Siteindependently integrated transgenes in the elite restorer rice line Minghui 63 allow removal of a selectable marker from the gene of interest by self-segregation. Plant Biotech J 2003, 1:155-165.

37. Wang D, Zhao Q, Zhu D, Ao G, Yu J: Particle-bombardment-mediated co-transformation of maize with a lysine rich protein gene (sb401) from potato. Euphytica 2006, 150:75-85.

38. Zhao Y, Qian Q, Wang HZ, Huang DN: Co-transformation of gene expression cassettes via particle bombardment to generate safe transgenic plant without any unwanted DNA. In Vitro Cell Dev Biol- Plant 2007, 43:328-334.

39. Matzke MA, Matzke AJM: How and why do plants inactivate homologous transgenes? Plant Physiol 1995, 107:679-685.

40. Muskens MWM, Vissers APA, Mol JNM, Kooter JM: Role of inverted DNA repeats in transcriptional and post-transcriptional gene silencing. Plant Mol Biol 2000, 43:243-260.

41. Wang MB, Waterhouse PM: High-efficiency silencing of a beta-glucuronidase gene in rice is correlated with repetitive transgene structure but is independent of DNA methylation. Plant Mol Biol 2000, 43:67-82.

42. Park J, Lee YK, Kang BK, Chung WI: Co-transformation using a negative selectable marker gene for the production of selectable marker genefree transgenic plants. Theor Appl Genet 2004, 109:1562-1567.

43. Gleave AP, Mitra DS, Mudge SR, Morris BAM: Selectable marker-free transgenic plants without sexual crossing: transient expression of cre recombinase and use of a conditional lethal dominant gene. Plant $\mathrm{Mol}$ Biol 1999, 40:223-235.

44. Rommens CM, Humara JM, Ye J, Yan H, Richael C, Zhang L, Perry R, Swords $\mathrm{K}$ : Crop improvement through modification of the plant's own genome. Plant Physiol 2004, 135:421-431

45. Schaart JG, Krens FA, Pelgrom KTB, Mendes O, Rouwendal JA: Effective production of marker-free transgenic strawberry plants using inducible site-specific recombination and a bifunctional selectable marker gene. Plant Biotechnol J 2004, 2:233-240.

46. Dutt M, Li LT, Dhekney SA, Gray DJ: A co-transformation system to produce transgenic grapevines free of marker genes. Plant Sci 2008, 175:423-430.

47. Ramana Rao MV, Veluthambi K: Selectable marker elimination in the $T_{0}$ generation by Agrobacterium-mediated co-transformation involving Mungbean yellow mosaic virus TrAP as a non-conditional negative selectable marker and bar for transient positive selection. Plant Cell Rep 2010, 29:473-483.

48. Schlaman HRM, Hooykaas PJJ: Effectiveness of the bacterial gene $\operatorname{cod} A$ encoding cytosine deaminase as a negative selectable marker in Agrobacterium-mediated plant transformation. Plant J 1997, 11:1377-1385

49. Hashimoto RY, Menck CFM, Van Sluys MA: Negative selection driven by cytosine deaminase gene in Lycopersicon esculentum hairy roots. Plant Sci 1999, 141:175-181.

50. Koprek T, McElroy D, Louwerse J, Williams-Carrier R, Lemaux PG: Negative selection systems for transgenic barley (Hordeum vulgare L.): comparison of bacterial codA-and cytochrome P450-mediated selection. Plant J 1999, 19:719-726

51. Eklof S, Astot C, Sitbon F, Moritz T, Olsson O, Sandberg G: Transgenic tobacco plants co-expressing Agrobacterium iaa and ipt genes have wild-type hormone levels but display both auxin- and cytokinin-over producing phenotypes. Plant J 2000, 23:279-284.

52. Tirichine L, Herrera-Cervera JA, Stougaard J: Chapter 5.4 Ds gene-tagging In Lotus japonicus Handbook. Edited by Márquez AJ. Springer Press (Dordrecht); 2005.

53. Chung WI, Lee WY, Jeong JH, Park J, Hong S: Development of negative selection system by using E. coli argE gene and synthetic N-acetylated phosphinothricin. Abstract \#877, American Society of Plant Biologists meeting; 2003

54. Chen X, Yang W, Sivamani E, Bruneau AH, Wang B, Qu R: Selective elimination of perennial ryegrass by activation of a pro-herbicide through engineering E. coli argE gene. Mol Breeding 2005, 15:339-347.

55. O'keefe DP, Tepperman JM, Dean C, Leto KJ, Erbes DL, Odell JT: Plant expression of a bacterial cytochrome P450 that catalyzes activation of a sulfonylurea pro-herbicide. Plant Physio/ 1994, 105:473-482.

56. Werck-Reichhart D, Hehn A, Didierjean L: Cytochrome P450 for engineering herbicide tolerance. Trends Plant Sci 2000, 5:116-123.

57. Datta SK: Androgenic haploids: factors controlling development and its application in crop improvement. Current Sci 2005, 89:1870-1878.

58. Kapusi E, Hensel G, Coronado MJ, Broeders S, Marthe C, Otto I, Kumlehn J: Elimination of selectable marker genes via segregation of uncoupled T-DNAs in populations of doubled haploid barley. J. Verbr. Lebensm. 2007, 2:115.

59. Li Z, Fu YP, Liu WZ, Hu GC, Si HM, Tang KX, Sun ZX: Rapid generation of selectable marker-free transgenic rice with three target genes by co-transformation and anther culture. Rice Sci 2007, 14:239-246.

60. Fedoroff NV: in Mobile DNA. Edited by Douglas EB, Martha MH. Washington, DC: Am. Soc. Microbiol; 1989:375-411.

61. Cotsaftis O, Sallaud C, Breitler JC, Meynard D, Greco R, Pereira A Guiderdoni E: Transposon-mediated generation of T-DNA- and marker-free rice plants expressing a Bt endotoxin gene. Mol Breeding 2002, 10:165-180.

62. Ebinuma $H$, Sugita K, Matsunaga E, Yamakado M: Selection of marker-free transgenic plants using the isopentyl transferase gene. Proc Natl Acad Sci USA 1997, 94:2117-2121.

63. Schetelig MF, Scolari F, Handler AM, Kittelmann S, Gasperi G: Site-specific recombination for the modification of transgenic strains of the Mediterranean fruit fly Ceratitis capitata. Proc Natl Acad Sci USA 2009, 106:18171-18176.

64. Grindley NDF, Whiteson KL, Rice PA: Mechanisms of site-specific recombination. Annu Rev Biochem 2006, 75:567-605.

65. Dale E, Ow DW: Intra- and intermolecular site-specific recombination in plant cells mediated by bacteriophage P1 recombinase. Gene 1990, 91:79-85.

66. Dale $\mathrm{E}$, Ow DW: Gene transfer with subsequent removal of the selection gene from the host genome. Proc Natl Acad Sci USA 1991, 88:10558-10562.

67. Gidoni D, Srivastava V, Carmi N: Site-specific excisional recombination strategies for elimination of undesirable transgenes from crop plants. In Vitro Cell Dev Biol- Plant 2008, 44:457-467.

68. Coppoolse ER, de Vroomen MJ, Roelofs D, Smit J, van Gennip F, Hersmus BJM, Nijkamp HJJ, van Haaren MJJ: Cre recombinase expression can result in phenotypic aberrations in plants. Plant Mol Biol 2003, 51:263-279.

69. Kopertekh L, Jüttner G, Schiemann J: PVX-Cre-mediated marker gene elimination from transgenic plants. Plant Mol Biol 2004, 55:491-500.

70. Jia H, Pang $Y$, Chen $X$, Fang R: Removal of the selectable marker gene from transgenic tobacco plants by expression of Cre recombinase from a tobacco mosaic virus vector through Agroinfection. Transgenic Res 2006, 15:375-384.

71. Kopertekh L, Schiemann J: Agroinfiltration as a tool for transient expression of Cre recombinase in vivo. Transgenic Res 2005, 14:793-798.

72. Srivastava $V$, Ow DW: Single-copy primary transformants of maize obtained through the co-introduction of a recombinase-expressing construct. Plant Mol Biol 2001, 46:561-566.

73. Liu HK, Yang C, Wei ZM: Heat shock-regulated site-specific excision of extraneous DNA in transgenic plants. Plant Sci 2005, 168:997-1003.

74. Hoff T, Schnorr KM, Mundy JA: Recombinase-mediated transcriptional induction system in transgenic plants. Plant Mol Biol 2001, 45:41-49.

75. Zhang W, Subbarao S, Addae P, Shen A, Armstrong C, Peschke V, Gilbertson L: Cre/lox-mediated marker gene excision in transgenic maize (Zea mays L.) plants. Theor Appl Genet 2003, 107:1157-1168. 
76. Wang Y, Chen B, Hu Y, Li J, Lin Z: Inducible excision of selectable marker gene from transgenic plants by the Cre/lox site-specific recombination system. Transgenic Res 2005, 14:605-614.

77. Cuellar W, Gaudin A, Solórzano D, Casas A, Nopo L, Chudalayandi P, Medrano G, Kreuze J, Ghislain M: Self-excision of the antibiotic resistance gene nptll using a heat inducible Cre-loxP system from transgenic potato. Plant Mol Biol 2006, 62:71-82.

78. Fladung $M$, Becker D: Elimination of marker genes and targeted integration via FLP/FRT recombination system from yeast in hybrid aspen (Populus tremula L. x P. tremuloides Michx.). Tree Genet Genom 2010, 6:205-217.

79. Zuo J, Niu QW, Møller SG, Chua NH: Chemical-regulated, site-specific DNA excision in transgenic plants. Nat Biotechnol 2001, 19:157-161.

80. Zuo J, Niu QW, Møller SG, Chua NH: An estrogen receptor-based transactivator XVE mediates highly inducible gene expression in transgenic plants. Plant J 2000, 24:265-273.

81. Matsunaga E, Sugita K, Ebinuma H: Asexual production of selectable marker-free transgenic woody plants, vegetatively propagated species. Mol Breeding 2002, 10:95-106.

82. Sreekala C, Wu L, Gu K, Wang D, Tian D, Yin Z: Excision of a selectable marker in transgenic rice (Oryza sativa L.) using a chemically regulated Cre/loxP system. Plant Cell Rep 2005, 24:86-94.

83. Zhang Y, Li H, Ouyang B, Lu Y, Ye Z: Chemical-induced autoexcision of selectable markers in elite tomato plants transformed with a gene conferring resistance to lepidopteran insects. Biotechnol Lett 2006, 28:1247-1253

84. Zhang Y, Liu H, Zhang JT, Li Y, Zhang H: Generation of selectable markerfree transgenic tomato resistant to drought, cold and oxidative stress using the Cre/loxP DNA excision system. Transgenic Res 2009, 18:607-619.

85. Woo HJ, Cho HS, Lim SH, Shin KS, Lee SM, Lee KJ, Kim DH, Cho YG: Autoexcision of selectable marker genes from transgenic tobacco via a stress inducible FLP/FRT site-specific recombination system. Transgenic Res 2009, 18:455-465.

86. Li Z, Xing A, Moon BP, Burgoyne SA, Guida AD, Liang H, et al: A Cre/loxPmediated self-activating gene excision system to produce marker gene free transgenic soybean plants. Plant Mol Biol 2007, 65:329-341.

87. Joubès J, De Schutter K, Verkest A, Inzé D, De Veylder L: Conditional recombinase-mediated expression of genes in plant cell cultures. Plant J 2004, 37:889-896.

88. Kondrák M, van der Meer IM, Bánfalvi Z: Generation of marker- and backbone-free transgenic potatoes by site-specific recombination and a bi-functional marker gene in a non-regular one-border Agrobacterium transformation vector. Transgenic Res 2006, 15:729-737.

89. Rio DC: Splicing of pre-mRNA: mechanism, regulation and role in development. Curr Opin Genet Dev 1993, 3:574-584.

90. Mlynárová L, Conner AJ, Nap JP: Directed microspore-specific recombination of transgenic alleles to prevent pollen-mediated transmission of transgenes. Plant Biotechnol J 2006, 4:445-452.

91. Luo K, Duan H, Zhao D, Zheng X, Deng W, Chen Y, Stewart CN Jr, McAvoy $R$, Jiang $X$, Wu Y, He A, Pei Y, Li Y: 'GM-gene-deletor': fused loxP-FRT recognition sequences dramatically improve the efficiency of FLP or CRE recombinase on transgene excision from pollen and seed to tobacco plants. Plant Biotechnol J 2007, 5:263-274.

92. Verweire D, Verleyen K, De Buck S, Claeys M, Angenon G: Marker-free transgenic plants through genetically programmed auto-excision. Plant Physiol 2007, 145:1220-1231.

93. Frédéric VE, Verweire D, Claeys M, Depicker A, Angenon G: Evaluation of seven promoters to achieve germline directed Cre-lox recombination in Arabidopsis thaliana. Plant Cell Rep 2009, 28:1509-1520.

94. Moon HS, Li Y, Stewart CN Jr: Keeping the genie in the bottle: transgene biocontainment by excision in pollen. Trends Biotechnol 2010, 28:3-8.

95. Day A, Goldschmidt-Clermont M: The chloroplast transformation toolbox: selectable markers and marker removal. Plant Biotechnol J 2011, 9:540-553.

96. Corneille S, Lutz KA, Azhagiri AK, Maliga P: Identification of functional lox sites in the plastid genome. Plant J 2003, 35:753-762.

97. Lutz K, Corneille S, Azhagiri AK, Svab Z, Maliga P: A novel approach to plastid transformation utilizes the phiC31 phage integrase. Plant J 2004, 37:906-913.

98. Lutz KA, Bosacchi MH, Maliga P: Plastid marker gene excision by transiently expressed CRE recombinase. Plant J 2006, 45:447-456.

99. Lutz KA, Svab Z, Maliga P: Construction of marker-free transplastomic tobacco using the Cre-loxP site-specific recombination system. Nat Protoc 2006, 1:900-910.
100. Chevalier BS, Stoddard BL: Homing endonucleases: structural and functional insight into the catalysts of intron/intein mobility. Nucleic Acids Res 2001, 29:3757-3774.

101. Gogarten JP, Senejani AG, Zhaxybayeva O, Olendzenski L, Hilario E: Inteins: structure, function, and evolution. Annu Rev Microbiol 2002, 56:263-287.

102. Thierry A, Dujon B: Nested chromosomal fragmentation in yeast using the meganuclease I-Scel: a new method for physical mapping of eukaryotic genomes. Nucleic Acids Res 1992, 20:5625-5631.

103. Jasin M: Genetic manipulation of genomes with rare-cutter endonucleases. Trends Genet 1996, 12:224-228.

104. Jacquier A, Dujon B: An intron-encoded protein is active in a gene conversion process that spreads an intron into a mitochondrial gene. Cell 1985, 41:383-394.

105. Siegl T, Petzke L, Welle E, Luzhetskyy A: I-Scel endonuclease: a new tool for DNA repair studies and genetic manipulations in streptomycetes. Appl Microbiol Biotechnol 2010, 87:1525-1532.

106. Puchta $H$, Dujon B, Hohn B: Homologous recombination in plant cells is enhanced by in vitro induction of double strand breaks into DNA by site-specific endonuclease. Nucleic Acids Res 1993, 21:5034-5040.

107. Donoho G, Jasin M, Berg P: Analysis of gene targeting and intrachromosomal homologous recombination stimulated by genomic double-strand breaks in mouse embryonic stem cells. Mol Cell Biol 1998, 18:4070-4078

108. Siebert H, Puchta H: Efficient repair of genomic double-strand breaks by homologous recombination between directly repeat sequences in plant genome. Plant Cell 2002, 14:1121-1131.

109. West CE, Waterworth WM, Sunderland PA, Bray CM: Arabidopsis DNA doublestrand break repair pathways. Biochem Soc Trans 2004, 32:964-966.

110. Swoboda P, Gal S, Hohn B, Puchta H: Intrachromosomal homologous recombination in whole plants. EMBO J 1994, 13:484-489.

111. Bertrand P, Rouilard D, Boulet A, Levalois C, Soussi T, Lopez BS: Increase of spontaneous intrachromosomal homologous recombination in mammalian cells expressing a mutant p53 protein. Oncogene 1997, 14:1117-1122.

112. Puchta $\mathrm{H}$, Hohn B: From centiMorgans to basepairs: homologous recombination in plants. Trends Plant Sci 1996, 1:340-348.

113. Zubko E, Scutt C, Meyer P: Intrachromosomal recombination between attP regions as a tool to remove selectable marker genes from tobacco transgenes. Nat Biotechnol 2000, 18:442-445.

114. Puchta H: Removing selectable marker genes: taking the shortcut. Trends Plant Sci 2000, 5:273-274

115. Porteus $\mathrm{MH}$, Carroll D: Gene targeting using zinc finger nucleases. Nat Biotechnol 2005, 23:967-973.

116. Salomon S, Puchta H: Capture of genomic and T-DNA sequences during double-strand break repair in somatic plant cells. EMBO J 1998, 17:6086-6095

117. Chilton MM, Que Q: Targeted integration of T-DNA into the tobacco genome at double-stranded breaks: new insights on the mechanism of T-DNA integration. Plant Physiol 2003, 133:956-965.

118. Kim YG, Cha J, Chandrasegaran S: Hybrid restriction enzymes: zinc finger fusions to Fok I cleavage domain. Proc Natl Acad Sci USA 1996, 93:1156-1160.

119. Liu PQ, Chan EM, Cost GJ, Zhang L, Miller JC, Guschin DY, Reik A, Holmes MC, Mott JE, Mott TN, Gregory PD: Generation of a triple-gene knockout mammalian cell line using engineered zinc-finger nucleases. Biotehnol Bioeng 2010, 106:97-105.

120. Lee HJ, Kim E, Kim JS: Site-specific DNA excision via engineered zinc finger nucleases. Trends Biotechnol 2010, 28:445-446.

121. Weinthal D, Tovkach A, Zeevi V, Tzfira T: Genome editing in plant cells by zinc finger nucleases. Trends Plant Sci 2010, 15:308-321.

122. Cai CQ, Doyon Y, Ainley WM, Miller JC, Dekelver RC, Moehle EA, Rock JM, Lee $Y L$, Garrison $R$, Schulenberg $L$, et al: Targeted transgene integration in plant cells using designed zinc finger nucleases. Plant Mol Biol 2009, 69:699-709.

123. Shukla VK, Doyon Y, Miller JC, Dekelver RC, Moehle EA, Worden SE, Mitchell JC, Arnold NL, Gopalan S, Meng X, et al: Precise genome modification in the crop species Zea mays using zinc-finger nucleases. Nature 2009, 459:437-441.

124. Townsend JA, Wright DA, Winfrey RJ, Fu F, Maeder ML, Joung JK, Voytas DF: High-frequency modification of plant genes using engineered zinc-finger nucleases. Nature 2009, 459:442-445.

125. Osakabe K, Osakabe Y, Toki S: Site-directed mutagenesis in Arabidopsis using custom-designed zinc finger nucleases. Natl Acad Sci USA 2010, 107:12034-12039. 
126. Zhang F, Maeder ML, Unger-Wallace E, Hoshaw JP, Reyon D, Christian M, Li X, Pierick CJ, Dobbs D, Peterson T, Joung JK, Voytase DF: High frequency targeted mutagenesis in Arabidopsis thaliana using zinc finger nucleases. Proc Natl Acad Sci USA 2010, 107:12028-12033.

127. Petolino JF, Worden A, Curlee K, Connell J, Moynahan TLS, Larsen C, Russell S: Zinc finger nuclease-mediated transgene deletion. Plant Mol Biol 2010, 73:617-628

128. Nain $V$, Jaiswal $R$, Dalal M, Ramesh B, Kumar PA: Polymerase chain reaction analysis of transgenic plants contaminated by Agrobacterium. Plant $\mathrm{Mol}$ Biol Rep 2005, 23:59-65.

129. Hooykaas PJJ, Schilperoort RA: Agrobacterium and plant genetic engineering. Plant Mol Biol 1992, 19:15-38.

130. Miura A, Yonebayashi S, Watanabe K, Toyama T, Shimada H, Kakutani T: Mobilization of transposons by a mutation abolishing full DNA methylation in Arabidopsis. Nature 2001, 411:212-214.

131. Lee HJ, Kim E, Kim JS: Targeted chromosomal deletions in human cells using zinc finger nucleases. Genome Res 2010, 20:81-89.

132. USDA/APHIS Environmental Assessment: In response to Monsanto Petition 04-229-01P Seeking a Determination of Nonregulated Status for Lysine Maize line LY038. www.asphis.usda.gov.

133. Buchholz F: Engineering DNA processing enzymes for the postgenomic era. Curr Opin Biotechnol 2009, 20:383-389.

134. Naiche LA, Papaioannou VE: Cre activity causes widespread apoptosis and lethal anemia during embryonic development. Genesis 2007, 45:768-775.

135. Liu J, Skjorringe T, Gjetting T, Jensen TG: PhiC31 integrase induces a DNA damage response and chromosomal rearrangements in human adult fibroblasts. BMC Biotechnol 2009, 9:31.

136. Srivastava V, Ow DW: Rare instances of Cre-mediated deletion product maintained in transgenic wheat. Plant Mol Biol 2002, 52:661-668.

137. Kittiwongwattana C, Lutz K, Clark M, Maliga P: Plastid marker gene excision by the phiC31 phage site-specific recombinase. Plant Mol Biol 2007, 64:137-143

138. Bendich AJ: Why do chloroplasts and mitochondria contain so many copies of their genome? Bioassays 1987, 6:279-282.

139. Sauer B: Identification of cryptic lox sites in the yeast genome by selection for Cre-mediated chromosome translocations that confer multiple-drug resistance. J Mol Biol 1992, 223:911-928.

140. Thyagarajan B, Guimarães MJ, Groth AC, Calos MP: Mammalian genomes contain active recombinase recognition sites. Gene 2000 244:47-54.

141. Olivares EC, Hollis RP, Chalberg TW, Meuse L, Kay MA, Calos MP: Sitespecific genomic integration produces therapeutic Factor IX levels in mice. Nat Biotechnol 2002, 20:1124-1128.

142. Keravala A, Groth AC, Jarrahian S, Thyagarajan B, Hoyt JJ, Kirby PJ, Calos MP: A diversity of serine phage integrases mediate site-specific recombination in mammalian cells. Mol Gen Gent 2006, 276:135-146.

143. Thomson JG, Chan R, Thilmony R, Yau YY, Ow DW: PhiC31 recombination system demonstrates heritable germinal transmission of site-specific excision from the Arabidopsis genome. BMC Biotechnol 2010, 10:17.

144. Qin M, Bayley C, Stockton T, Ow DW: Cre recombinase-mediated sitespecific recombination between plant chromosomes. Proc Natl Acad Sci USA 1994, 91:1706-1710.

145. Koshinsky HA, Lee E, OW DW: Cre-lox site-specific recombination between Arabidopsis and tobacco chromosomes. Plant J 2000, 23:715-722.

146. Medberry SL, Dale E, Qin M, Ow DW: Intra-chromosomal rearrangements generated by Cre-lox site specific recombination. Nucleic Acids Res 1995, 23:485-490.

147. Schmidt EE, Taylor DS, Prigge JR, Barnett S, Capecchi MR: Illegitimate Credependent chromosome rearrangements in transgenic mouse spermatides. Proc Natl Acad Sci USA 2000, 97:13702-13707.

148. Varshney RK, Nayak SN, May GD, Jackson SA: Next-generation sequencing technologies and their implications for crop genetics and breeding. Trends Biotechnol 2009, 27:522-530.

149. Moon HS, Abercrombie LL, Eda S, Blanvillain R, Thomson JG, Ow DW, Stewart CN Jr: Transgene excision in pollen using a codon optimized serine resolvase $\mathrm{CinH}-\mathrm{RS} 2$ site-specific recombination system. Plant $\mathrm{Mol}$ Biol 2011, 75:621-631.

150. Srivastava V, Ow DW: Marker-free site-specific gene integration in plants. Trends Biotechnol 2004, 22:627-629.
151. Akbudak MA, Srivastava V: Improved FLP recombinase, FLPe, efficiently removes marker gene from transgene locus developed by Cre-lox mediated site-specific gene integration in rice. Mol Biotechnol 2011, 9:82-89.

152. Thomson JG, Yau YY, Blanvillain R, Nunes WM, Chiniquy D, Thilmony R, Ow DW: ParA resolvase catalyzes site-specific excision of DNA from the Arabidopsis genome. Transgenic Res 2009, 18:237-248.

153. Zhou Y, Yau YY, Ow DW, Wang Y: Site-specific deletions in the tomato genome by the $\mathrm{CinH}-\mathrm{RS} 2$ and ParA-MRS recombination systems. Plant Biotechnol Rep 2012, 6:225-232.

154. Thomson JG, Chan R, Smith J, Thilmony R, Yau YY, Wang Y, Ow DO: The Bxb1 recombination system demonstrates heritable transmission of sitespecific excision in Arabidopsis. BMC Biotechnol 2012, 12:9.

155. Blechl A, Lin J, Shao M, Thilmony R, Thomson J: The Bxb1 recombinase mediates site-specific deletion in transgenic wheat. Plant Mol Biol Rep 2012, 30:1357-1366

156. Yamaguchi S, Kazuki Y, Nakayama Y, Nanba E, Oshimura M, Ohbayashi T: A method for producing transgenic cells using a multi-integrase system on a human artificial chromosome vector. PLoS One 2011, 6:e17267.

157. Le Y, Gagneten S, Tombaccini D, Bethke B, Sauer B: Nuclear targeting determinants of the phage P1 Cre DNA recombinase. Nucleic Acids Res 1999, 27:4703-4709.

158. Will E, Klump H, Heffner N, Schwieger M, Schiedlmeier B, Ostertag W, Baum C Stocking C: Unmodified Cre recombinase crosses the membrane. Nucleic Acids Res 2002, 30:e59.

159. Andreas S, Schwenk F, Küter-Luks B, Faust N, Kühn R: Enhanced efficiency through nuclear localization signal fusion on phage $\varphi$ C31-integrase: activity comparison with Cre and FLPe recombinase in mammalian cells. Nucleic Acids Res 2002, 30:2299-2306.

160. Brown WRA, Lee NCO, Xu Z, Smith MCM: Serine recombinases as tools for genome engineering. Methods 2011, 53:372-379.

161. Raymond CS, Soriano P: High-efficiency FLP and $\varphi C 31$ site-specific recombination in mammalian cells. PLoS One 2007, 2:e162.

162. Shao M, Thomson J: A rapid and quantitative recombinase activity assay. Abstract (P120), Plant and Animal Genome XIX conference. San Diego; 2011. http://www.intl-pag.org.

163. Day CD, Lee E, Kobayashi J, Holappa LD, Albert HA, Ow DW: Transgene integration into the same chromosome location can produce alleles that express at a predictable level, or alleles that are differentially silenced. Genes Dev 2000, 14:2869-2880.

164. Wimmer EA: Insect transgenesis by site-specific recombination. Nat Methods 2005, 2:580-582.

165. Hockemeye D, Soldner F, Beard C, Gao Q, Mitalipova M, Dekelver RC, Katibah GE, Amora R, Boydston EA, Zeitler B, et al: Efficient targeting of expressed and silent genes in human ESCs and iPSCs using zinc-finger nucleases. Nat Biotechnol 2009, 27:851-857.

166. Zou J, Maeder M, Mali P, Pruett-Miller SM, Thibodeau-Beganny S, Chou $B K$, et al: Gene targeting of a disease-related gene in human induced pluripotent stem and embryonic stem cells. Cell Stem Cell 2009, 5:97-110

167. Yau YY, Wang YJ, Thomson JG, OW DW: Method for Bxb1-mediated sitespecific integration in planta. (Ed.) James A. Birchler. In Plant Chromosome Engineering: Method in Molecular Biology, Vol. 701. Clifton, New Jersey: Humana Press; 2011:147-166.

168. Büttner D, Bonas U: Regulation and secretion of Xanthomonas virulence factors. FEMS Microbiol Rev 2010, 34:107-133.

169. Kay S, Hahn S, Marois E, Hause G, Bonas U: A bacterial effector acts as a plant transcription factor and induces a cell size regulator. Science 2007, 318:648-651.

170. Li T, Huang S, Jiang WZ, Wright D, Spalding MH, Weeks DP, Yang B: TAL nucleases (TALNs) hybrid proteins composed of TAL effectors and FokI DNAcleavage doman. Nucleic Acids Res 2011, 39:359-372.

171. Scholze $H$, Boch J: TAL effectors are remote controls for gene activation. Curr Opin Microbiol 2011, 14:47-53.

172. Cade L, Reyon D, Hwang WY, Tsai SQ, Patel S, Khayter C, Joung JK, Sander JD, Peterson RT, Yeh JR: Highly efficient generation of heritable zebrafish gene mutations using homo- and heterodimeric TALENs. Nucleic Acids Res 2012, 40:8001-8010

173. Tesson L, Usal C, Menoret S, Leung E, Niles BJ, Remy S, et al: Knockout rats generated by embryo microinjection of TALENs. Nat Biotechnol 2011, 29:695-696. 
174. Cermak T, Doyle EL, Christian M, Wang L, Zhang Y, Schmidt C, Baller JA, et al: Efficient design and assembly of custom TALEN and other TAL effectorbased constructs for DNA targeting. Nucleic Acids Res 2011, 39:e82.

175. Li T, Liu B, Spalding MH, Weeks DP, Yang B: High-efficiency TALEN-based gene editing produces disease-resistant rice. Nat Biotechnol 2012, 30:390-392.

176. Mentewab A, Stewart CN Jr: Overexpression of an Arabidopsis thaliana $\mathrm{ABC}$ transporter confers kanamycin resistance to transgenic plants. Nat Biotechnol 2005, 23:1177-1189.

177. Burris KA, Mentewab A, Ripp S, Stewart CN Jr: An Arabidopsis thaliana ABC transporter that confers kanamycin resistance in transgenic plants does not endow resistance to Escherichia coli. Microbial Biotechnol 2008, 1:191-195.

doi:10.1186/1472-6750-13-36

Cite this article as: Yau and Stewart: Less is more: strategies to remove marker genes from transgenic plants. BMC Biotechnology 2013 13:36.

\section{Submit your next manuscript to BioMed Central and take full advantage of:}

- Convenient online submission

- Thorough peer review

- No space constraints or color figure charges

- Immediate publication on acceptance

- Inclusion in PubMed, CAS, Scopus and Google Scholar

- Research which is freely available for redistribution 